\title{
CRITICAL MAKING: CONTEMPORARY FASHION PRACTICES
}

\author{
Margo Barton, Jane Malthus and Moira White
}

\section{INTRODUCTION}

The 2020 fashion symposium associated with iD Dunedin Fashion week was originally envisioned as part of an exhibition where participants would talk about critical making in conjunction with their exhibited fashion outcome. Planned for 6 June 2020, a broad call went out early in the year to those involved in the many aspects of making relevant work that reflected imagination and identity, from hairdressing and makeup to jewellery, as well as designers working with textiles and other materials in the area of fashion. All fashion practitioners, traditional or experimental, emerging or established, were welcome.

Those interested in participating were asked to submit:

- A 300-500-word abstract which outlined the thinking behind their work

- Photographs of the work to be exhibited

- Up to three photographs of examples of their previous work

- A one-page CV with bio, explaining their fashion background and experience, and links to their Instagram account and website if applicable.

Submissions were to be assessed by a curatorial team comprising Margo Barton, Jane Malthus and Moira White. All exhibitors needed to commit to travelling to Dunedin, to attend the symposium day and present their work to symposium attendees.

The Critical Making: Contemporary Fashion Practices Exhibition was to be on display from 4-7 June 2020, with the two days beforehand available for installation, and the symposium held on 6 June. The event was planned to coincide with the iD International Emerging Designer Awards, and to run alongside the Fashion Forward $>>$ Disruption Through Design exhibition at Otago Museum in Dunedin.

The global disruption caused by Covid-19 necessitated a rewrite of our call, alterations to the timetable for entries, a change to digital submissions and creation of an online symposium space. Potential exhibitors now needed to submit a short video presentation, and moving and still images, by 20 May 2020. Those selected were included in the symposium exhibition site www.contemporaryfashionpractices.com, which finally went live in early October 2020.

We received nearly 40 entries from all parts of the world, the vast majority of which were from textile fashion designers, from which we selected 24 for the website. We thank all entrants for their participation. 
For many involved in the discipline of fashion, making things is usually a deeply felt need involving experimentation: engaging mind, emotion and hands with textiles and other materials to create fashion that clothes the human body. For our Critical Making: Contemporary Fashion Practices Exhibitio [correct?] we were looking for outcomes that demonstrated an intensity of questioning and examination during the design process. Why should these designs exist? What are the ideas they are expressing? What traditions do they grow out of? What are their influences? What materials will make them work best? How will they be made? Can I make them? What improvements can I make to the designs? Do they break rules or fashion new directions? Do they work on a human body? What happens to the designs when that body moves?

For us, citical making also involves investigations into materiality, such as experimenting with creating new forms of material, new ways of using old materials, different uses for new materials, and using materials not usually associated with garments. Does the design honour the material, or is the material being forced into forms it does not want to hold? What happens if that occurs? What histories, cultures, memories and emotions do the materials bring to the design? What connections between design and materials am I creating in my combinations?

Consideration of the body and person that will wear the fashions created is vital, too. Are the designs effective on the body and how do they affect the wearer? Do they provide comfort and protection - physical, an or emotional? What is their sensorial impact on the wearer and viewer?

Thinking and acting sustainably is critical for all of us. Trying not to add to climate change effects, but rather to act in ways that might reduce the ; using practices that are sustainable for people, the environment and one's design busines ; and thinking through the implications of one's choices in making fashio, are all explicit elements of fashion design practice now. We believe that the designers featured in this Critical Making: Contemporary Fashion Practices Exhibition demonstrate that they have integrated these multiple aspects of critical making. They have shown intuition, skill and reflection in their creative practices, challenging their own and others' assumptions and using multiple ways of knowing in their fashion outcomes. Here we briefly profile the selected designers, and encourage you to visit the Contemporary Fashion Practices website and each designer's social media for further insights into their designs.

We sincerely thank the Otago Polytechnic ResearcheOffice, and the Otago Polytechnic School of Design for their ongoing support through granting time and funding.

\section{Curatorial panel, convenors and authors:}

Margo Barton is Professor of Fashion, Otago Polytechnic, co-chair of iD Dunedin Fashion, and a milliner and fashion designer.

Jane Malthus is a dress historian and honorary curator for the dress collection at Otago Museum, Dunedin, with qualifications in textiles, clothing and fashion, history and fine arts.

Moira White is Curator, Humanities at Otago Museum, Dunedin, and secretary of the Costume and Textile Association of New Zealand. 


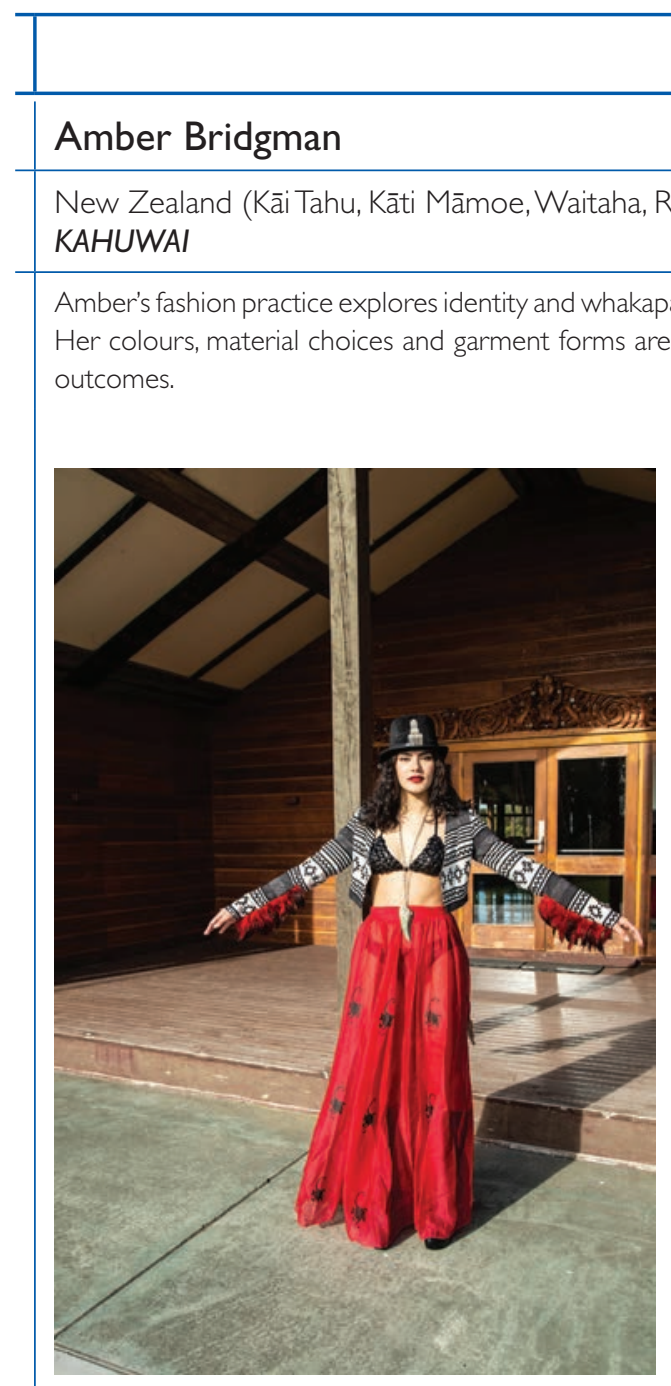

Figure I. Kahuwai, Amber Bridgman. Model Inez.

Location Kāti Huirapa ki Puketeraki.

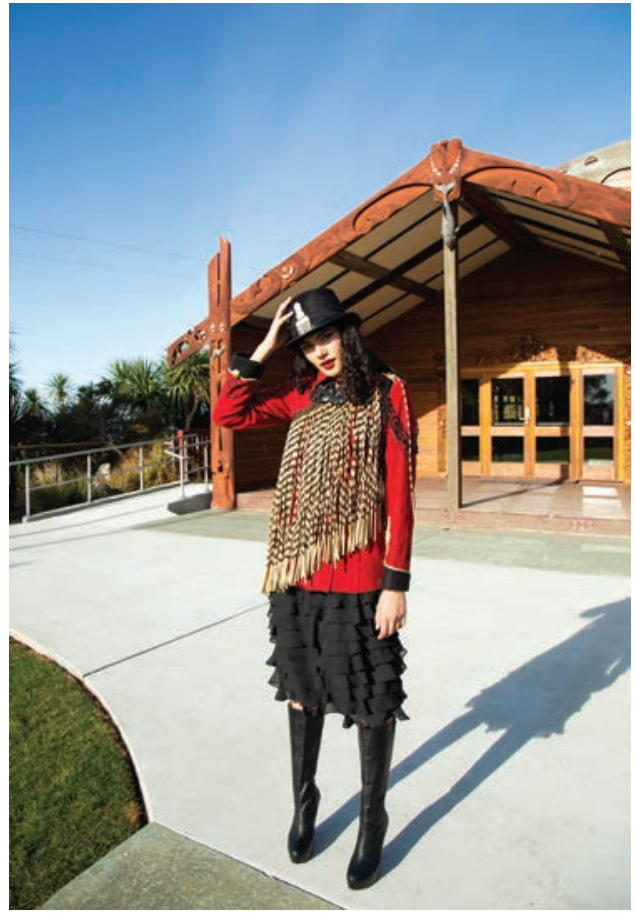

Figure 2. Kahuwai, Amber Bridgman. Model Inez.

Location Kāti Huirapa ki Puketeraki.

Fashion designer, artist and traditional weaver Amber Bridgman, who is of Kāi Tahu, Kāti Māmoe, Waitaha, Rabuvai and Aboriginal descent, is the wahine behind KAHUWAI, a Māori-owned and operated clothing and traditional Māori Arts label

\begin{tabular}{ll} 
website: & https://www.kahuwai.co.nz/ \\
\hline instagram: & $@ k$ khuwai \\
\hline facebook: & $@ m a o r i k a k a h u$ \\
\hline
\end{tabular}
that explores identity and whakapapa through its unique Māori designs in Aotearoa New Zealand.

https://www.contemporaryfashionpractices.com/curated-space-2020/0I-amber-bridgeman 


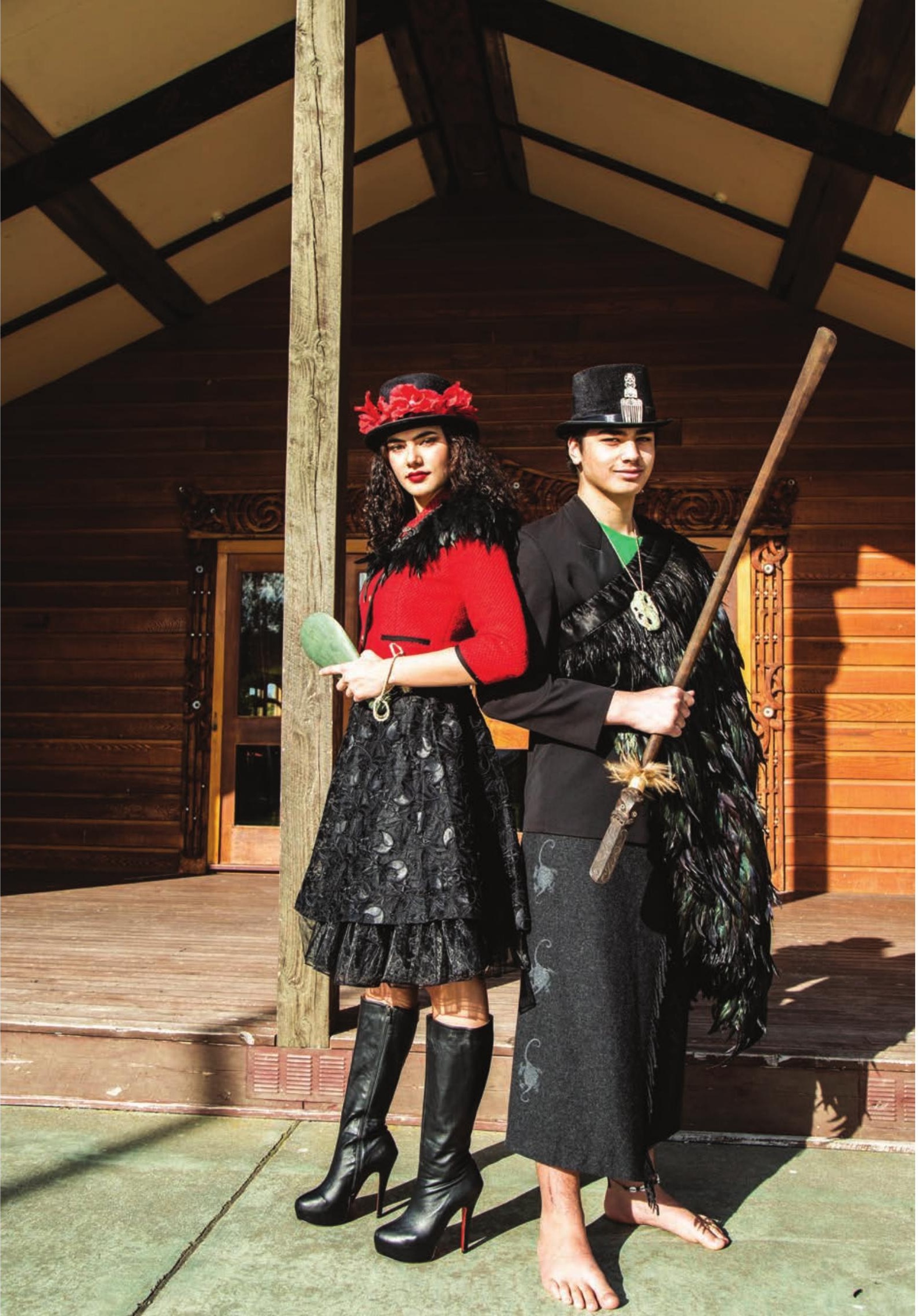




\section{Charlotte $Ø$ stergaard}

Denmark, Lund University, Sweden

AweAre

Working at the intersection of textiles, costume, fashion and performance, Charlotte's clever investigation of powe - controlling, imposing, manipulatin, or otherwise influencing the behaviour of other - involved a serious but playful relationship with her material, and a combination of weaving, knitting and braiding to achieve her four connected torso pieces to be worn by dancers.

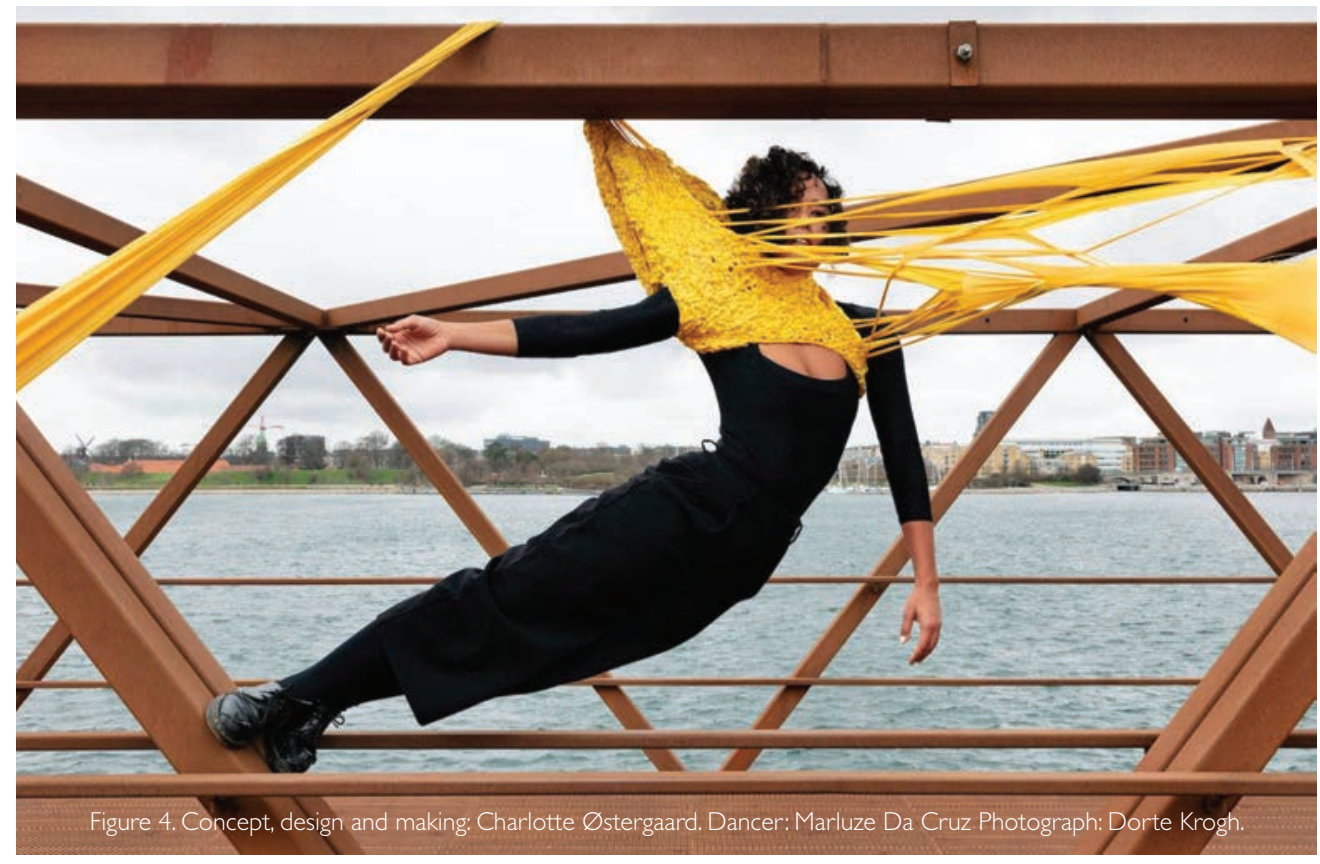

Charlotte Østergaard is a Danish costume, textile and fashion designer and teacher, and an independent artist. Charlotte's artworks have been exhibited internationally at curated exhibitiony, and are represented in the collections of the Danish Design Museum and The National Gallery of Denmark. In 2019 Charlotte's designs were presented at the 14 th Prague Quadrennial of Performance Design and Space, Innovative Costume of the 2Ist Century: The Next Generation (Moscow) and at The Biennale for Craft and Design (Copenhagen). She is currently PhD fellow at Malmö Theater Academy, Faculty of Fine and Performing Arts, at Lund University, Sweden.

\begin{tabular}{ll} 
website: & www.charlotteostergaardcopenhagen.dk \\
\hline email: & studio@charlotteostergaard.dk \\
\hline instagram: & unfoldingmyworld \\
\hline facebook: & $\begin{array}{l}\text { www.facebook.com/ } \\
\text { charlotteostergaardcopengagen }\end{array}$ \\
\hline vimeo: & vimeo.com/usercharlotteostergaard \\
\hline
\end{tabular}

https://www.contemporaryfashionpractices.com/curated-space-2020/0I-charlotte-ostergaard 


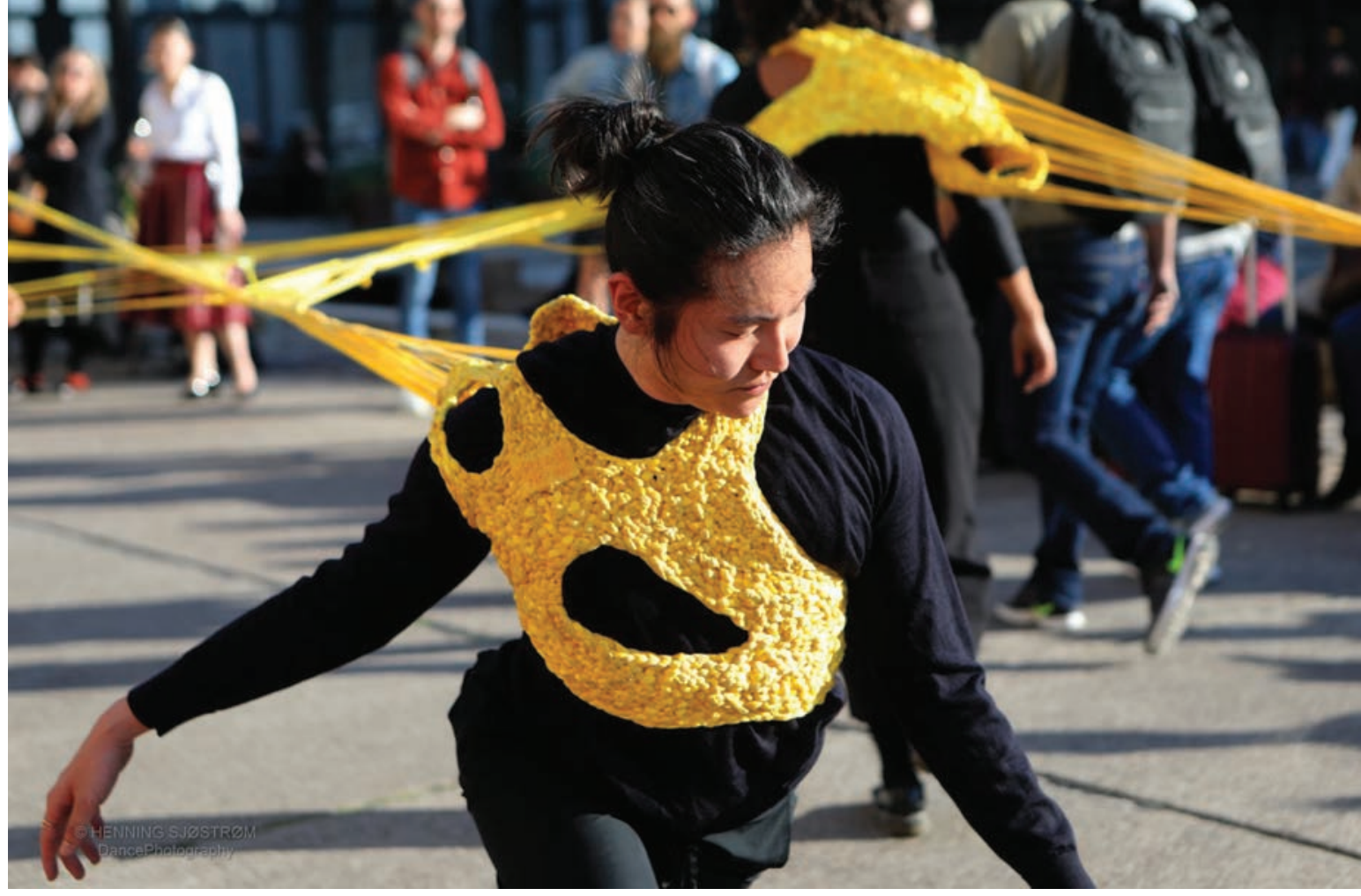

Figure 5. Concept, design and making: Charlotte Østergaard Performance: opening reception of

The Biennale for Crafts and Design, 2019.

Dancer: Daniel Jeremiah Persson.

Photograph: Henning Sjøstrøm.

Figure 6. Concept, design and making: Charlotte $\varnothing$ stergaard

Performance: UP CLOSE performance festival, 2020.

Dancers: Alex Berg, Camille Marchadour

Daniel Jeremiah Persson, Josefine Ibsen.

Photograph: Frida Gregersen.

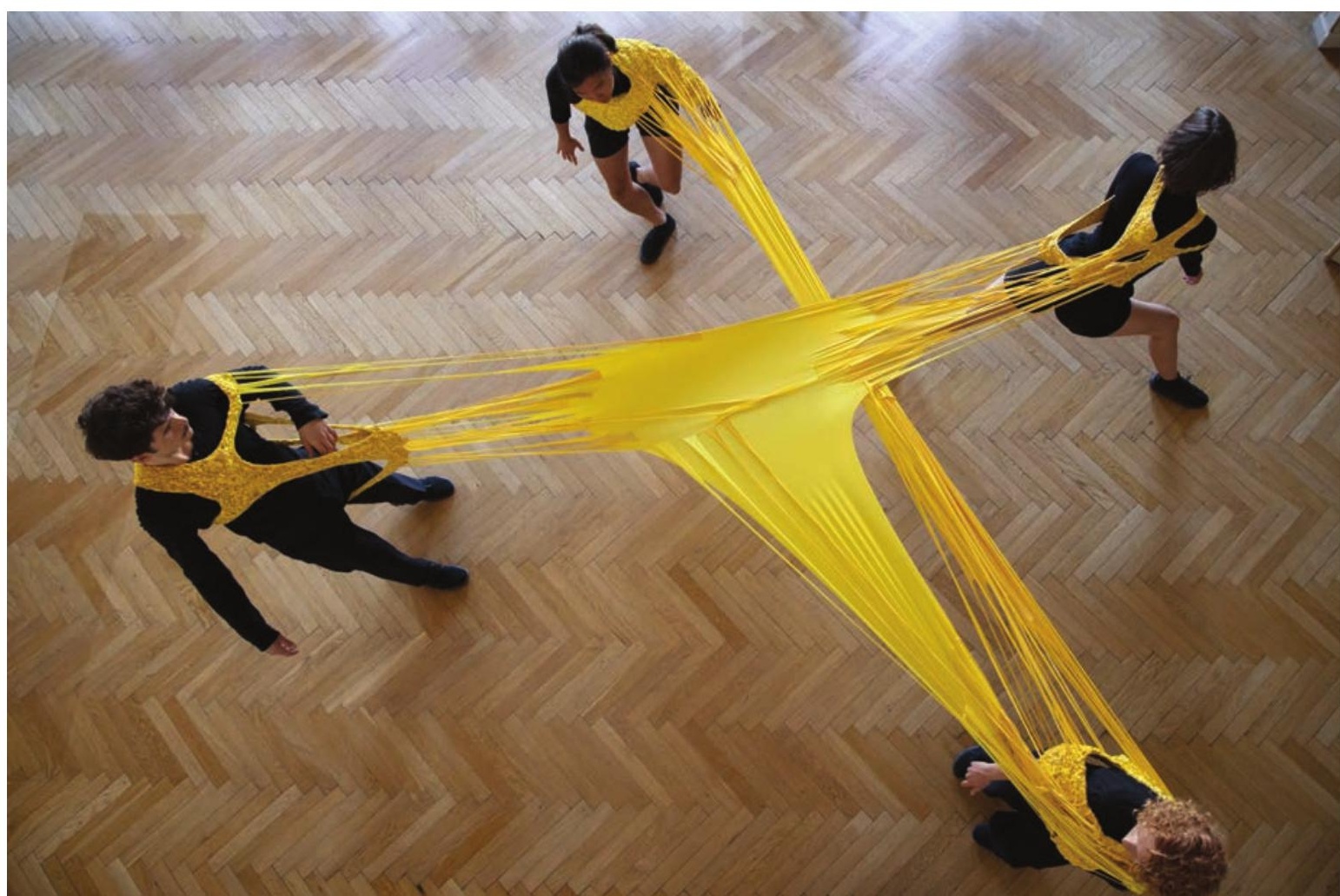




\section{Daphne Mohajer va Pesaran and Jake Nakashima-Edwards}

Australia / RMIT University, Melbourne

Kamiko Bomber

Daphne and Jake collaborated on pushing the limits of making garments from paper, specifically kamiko 'clot..' Washi, Japanese paper, was treated with starches and pastes, kneaded, layered and dyed, then used to make a durable bomber jacket. Daphne is part of the Endangered Material Knowledge Programme (https://www.emkp. org/paper-people-making-clothing-from-paper-in-japan/) hosted by the British Museum.

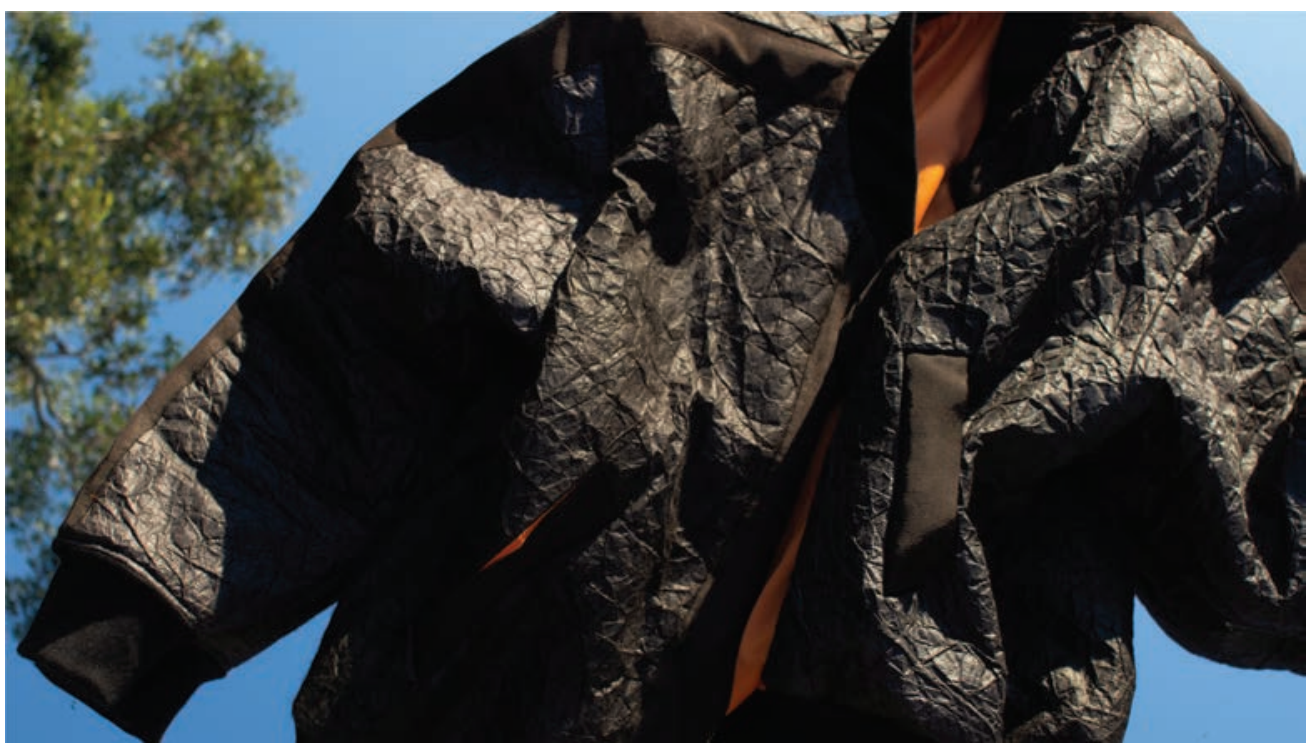

Figure 7. KAMIKO: Kamiko Bomber Jacket detail. Photograph: Jake Nakashima-Edwards.

\begin{tabular}{|c|c|c|}
\hline \multirow{3}{*}{$\begin{array}{l}\text { Daphne Mohajer va Pesaran lectures in fashion design } \\
\text { and research in The School of Fashion and Textiles at } \\
\text { RMIT University in Melbourne, Australia. In her research } \\
\text { and design practice she works with handmade Japanese } \\
\text { paper and garments made from paper. In } 2019 \text { the } \\
\text { Endangered Material Knowledge Program supported } \\
\text { her 'Paper people - Making clothing from paper in Japan' } \\
\text { project. She also uses film, drawing, text and audio in } \\
\text { storytelling and documentation. }\end{array}$} & website: & www.d-mvp.com \\
\hline & email: & $\begin{array}{l}\text { daphne.mohajer.va.pesaran@ } \\
\text { rmit.edu.au }\end{array}$ \\
\hline & social: & @daphne_mvp \\
\hline \multirow{2}{*}{$\begin{array}{l}\text { Jake Nakashima-Edwards is a recent graduate of the } \\
\text { Fashion Design program at RMIT University, Melbourne, } \\
\text { Australia, and is interested in how fashion intersects with } \\
\text { politics, capita, and the environment. His current practice } \\
\text { is centred on washi paper as a textile, and the connections } \\
\text { this material has with people, cultur, and nature. }\end{array}$} & email: & jake.naka@gmail.com \\
\hline & social: & @smiling.at.dogs \\
\hline
\end{tabular}

https://www.contemporaryfashionpractices.com/curated-space-2020/0 I-daphne-mohajer-va-pesaran 

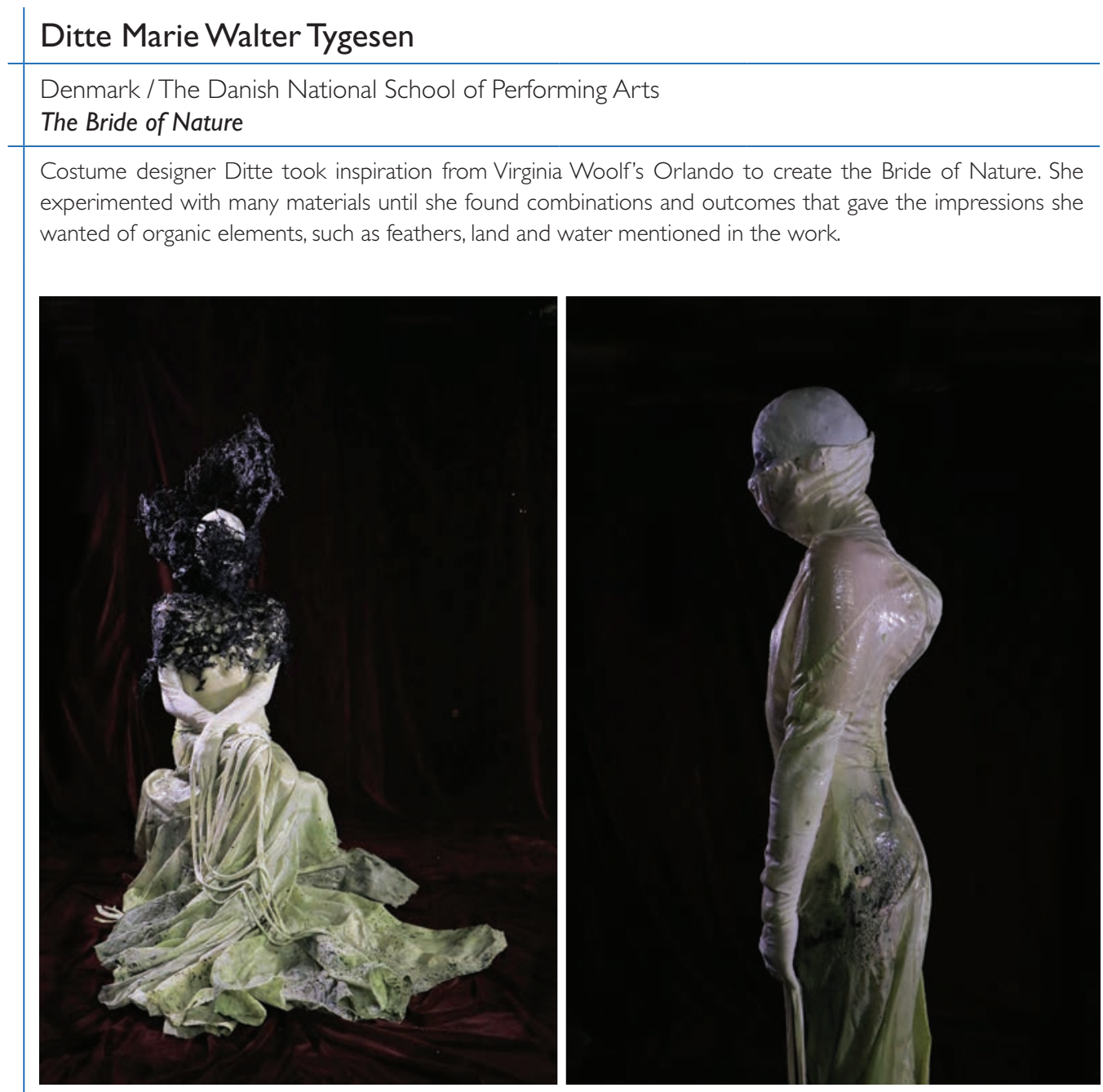

Figure 8. The bride of nature, Ditte Marie Walter Tygesen.

\begin{tabular}{|c|c|c|}
\hline \multirow{4}{*}{$\begin{array}{l}\text { Ditte Marie Walter Tygesen works as a visual } \\
\text { artist and designer in theatre, costume, sculpture } \\
\text { and textiles in Copenhagen. As a set and costume } \\
\text { designer at The Danish National School of } \\
\text { Performing Art, she has fallen in love with the whole } \\
\text { world of costume, especially the design and the } \\
\text { making or sculpting aspecdts. She use costumes as } \\
\text { scenography and the body as stage. Her costumes } \\
\text { are often highly theatrical and elaborate. }\end{array}$} & website: & https://www.dittetygesen.dk/ \\
\hline & email: & dittetygesen@gmail.com \\
\hline & instagram: & @hekseditte \\
\hline & & \\
\hline
\end{tabular}

https://www.contemporaryfashionpractices.com/curated-space-2020/0 I-ditte-marie-walter-tygesen 


\section{Divya N}

Fashion and jewellery designer and educator

India / National Institute of Fashion Technology, Chennai

Museum Piece

Inspired by spending time in museums, but aware of the museum gaze and the commodification of museum object - as well as the meanings of the phrase 'museum piece' when applied to peopl - Divya has created narrative jewellery. The model's performance for the camera was an important component of the work.

Figure 9. The Museum Piece by Divya N - A comment on museum gaze, commodification of art and the memory of it all.

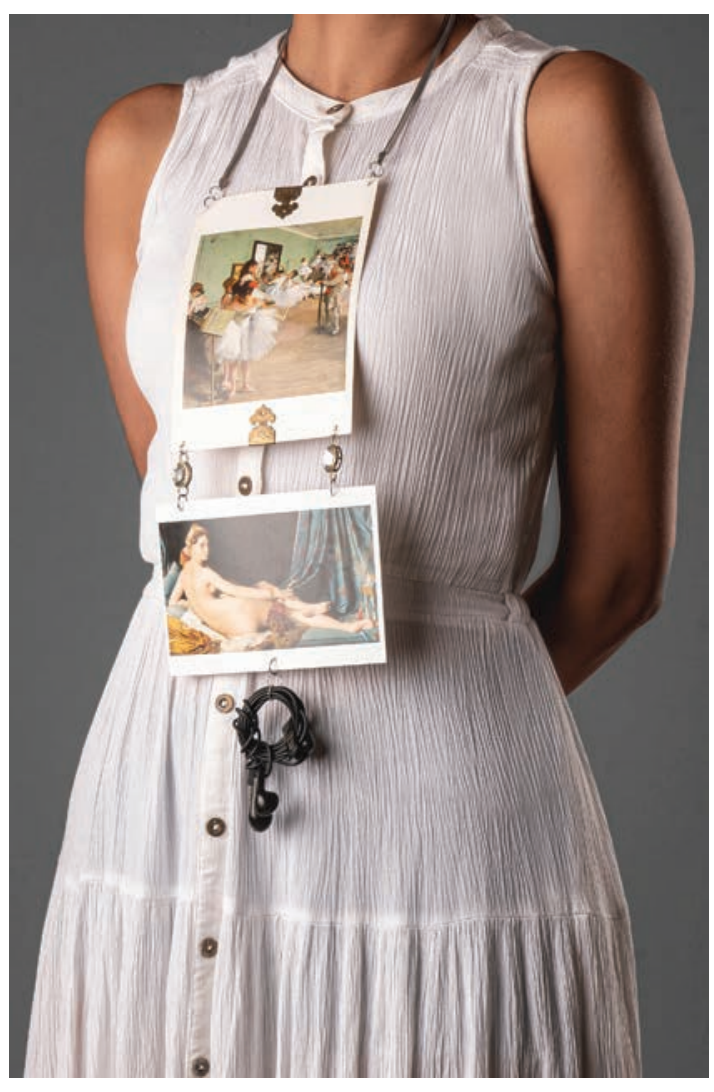

Divya $\mathrm{N}$ has degrees in apparel and fashion design, and in education. She has worked as an apparel designer for a number of brands. A self-taught jewellery designer, she launched her brand, Sayuri, in 2008. Over II years, she has created more

\begin{tabular}{ll} 
website: & https://www.jewelsofsayuri.com \\
\hline instagram: & @jewelsofsayuri \\
\hline facebook: & @jewelsofsayuri \\
\hline
\end{tabular}
than 2100 pieces of costume jewellery, including 12 thematic collections, and collaborated with other brands for specific projects. Divya has also worked as a fashion writer and authored a jewellery blog documenting the scope of contemporary jewellery in India. She is currently pursuing a PhD in contemporary jewellery design.

https://www.contemporaryfashionpractices.com/curated-space-2020/0 I-divya-n 


\section{Elizabeth Walecki}

UK / De Montfort University

Principles of Science and Dress: Matter, Form and Motion

Placing the body amid the scientific language of states of matter, and thinking of garments as solids and liquids, through this collection the designer asks if the wearer's actions and behaviour can alter those states, as garments can alter a wearer's perceptions? Elizabeth's background with knitted fabrics informed these experiments.
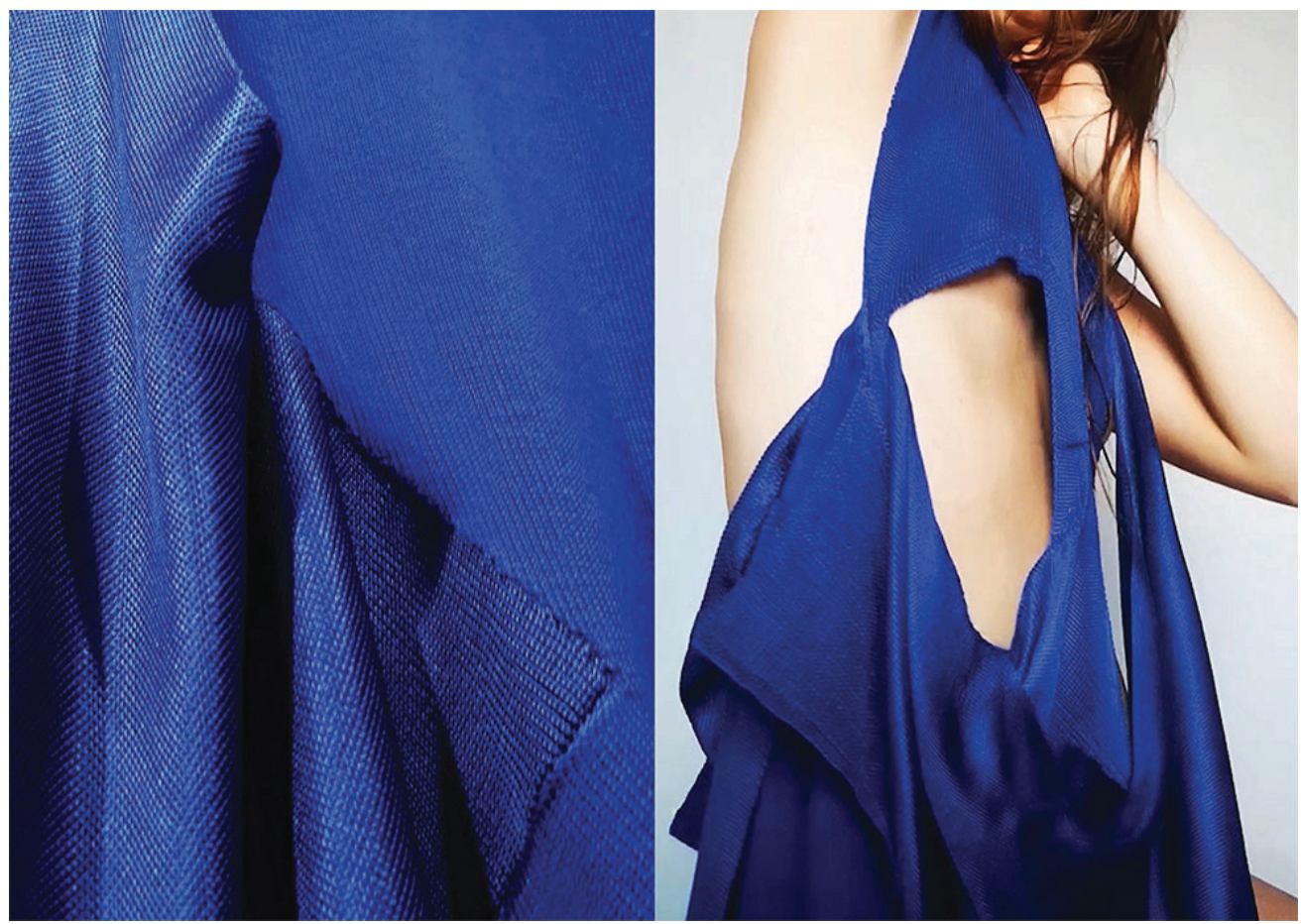

Figure 10. Solid vs liquid. Principles of Science and Dress. Elizabeth Walecki.

Elizabeth Walecki is a graduate of the Fashion Textiles and Accessories course at De Montfort University and assistant designer at AmLondon. She has previously worked at London-based knitwear label Christina Seewald. Walecki's own practice, which foregrounds design narrative, has been recognised through the Textile Society Award (2020), The Worshipful Company of Framework Knitters Bursary Award (2020) and The Roadley Sustainable Award (2020). 


\section{Donna Dinsdale}

New Zealand / Toi Ohomai Institute of Technology

Betty

'Bett' playfully symbolises gender issues as depicted in the 1950s, but which are just as relevant today. Women still have to juggle multiple roles and expectations while trying to fulfil their own needs and desires. Donna's art practice grew from her fashion designer background.

Figure 1 I. "Greet him with a warm smile and show sincerity in your desire to please him". Betty, Donna Dinsdale. Photograph: Anne Shirley.

Donna Dinsdale is an educator and practitioner specialising in fashion and design, in particular textiles and free-form draping. The aesthetic value of repurposed textiles and trims often drives her work. She utilises her reflective b-cultural perspective and personal lived experience in investigating, experimenting with and developing textiles into cultural artefacts. Donna is a tutor in The Bachelor of Creative Industries at Toi Ohomai Institute of Technology in Tauranga.

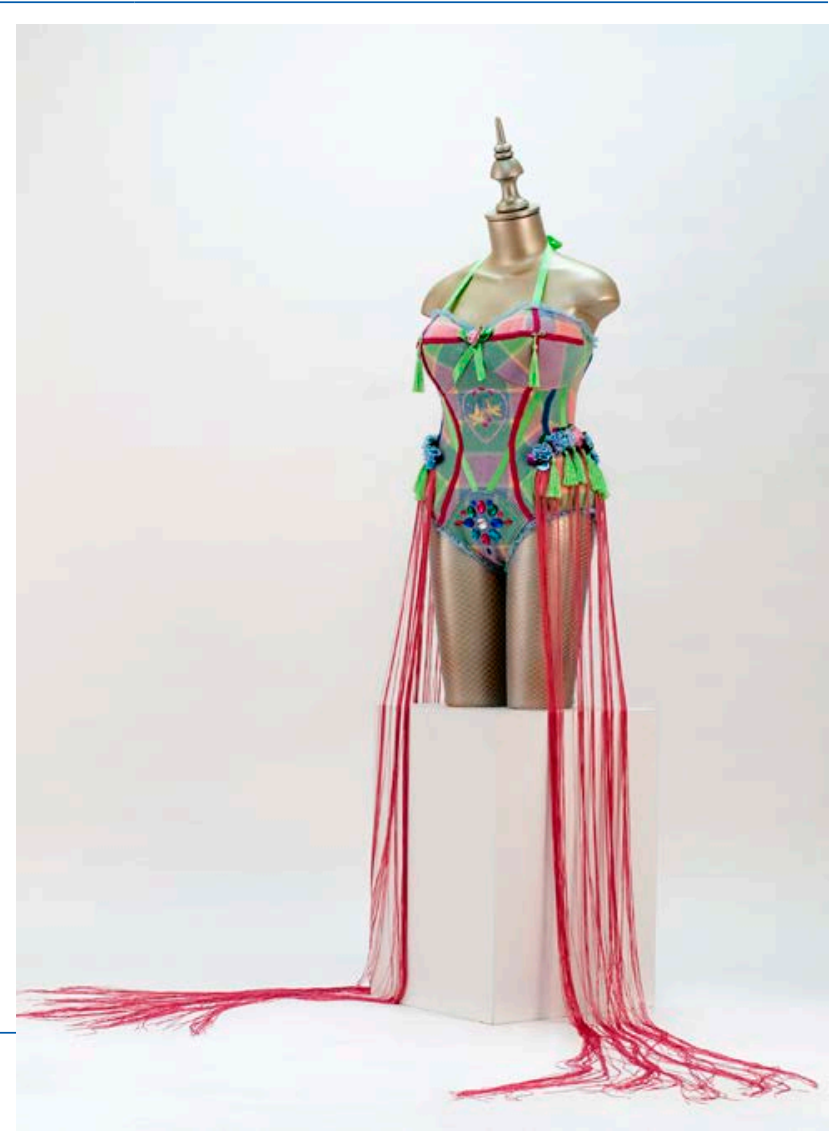

website: Masters of Art and Design thesis: http://aut. researchgateway.ac.nz/handle//0292/89/3

website: Hokonui Fashion Design Awards: https://www.stuff.co.nz/ national/I I 4529772/donna-dinsdales-menswear-entrywins-hokonui-fashion-design-awards

website: Westfield Style Pasifika Fashion Awards: https:// designerdirection.wordpress.com/2009/08/26/bay-fashionstudents-dominate-at-westfield-style-pasifika-awards/

email: Donna.Dinsdale@toiohomai.ac.nz 


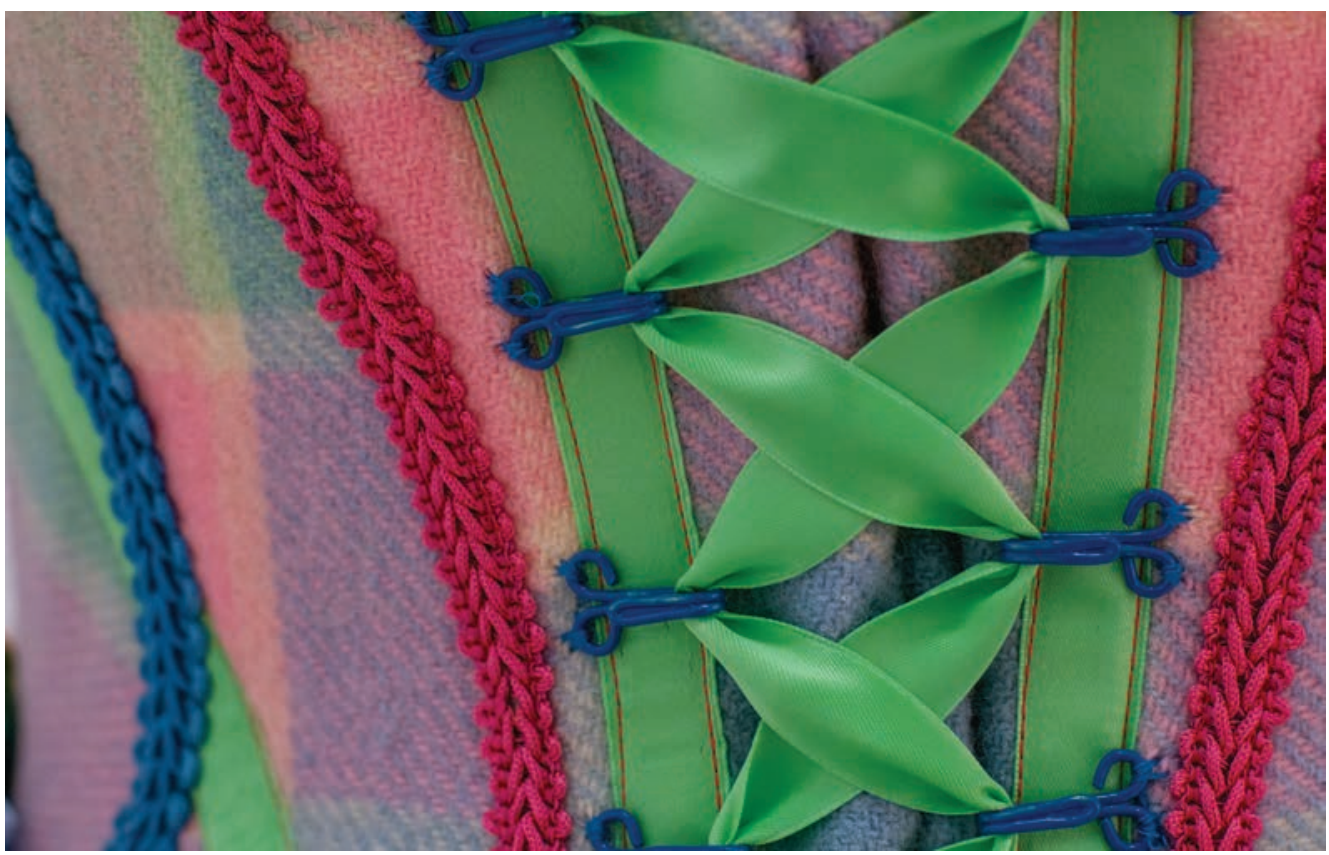

Figure 12. "Put a ribbon in your hair and be fresh-looking". Betty, Donna Dinsdale. Photograph: Anne Shirley.

Figure 13. "Remember, he is the master of the house and as such will always exercise his will with fairness and truthfulness". Betty, Donna Dinsdale. Photograph: Anne Shirley

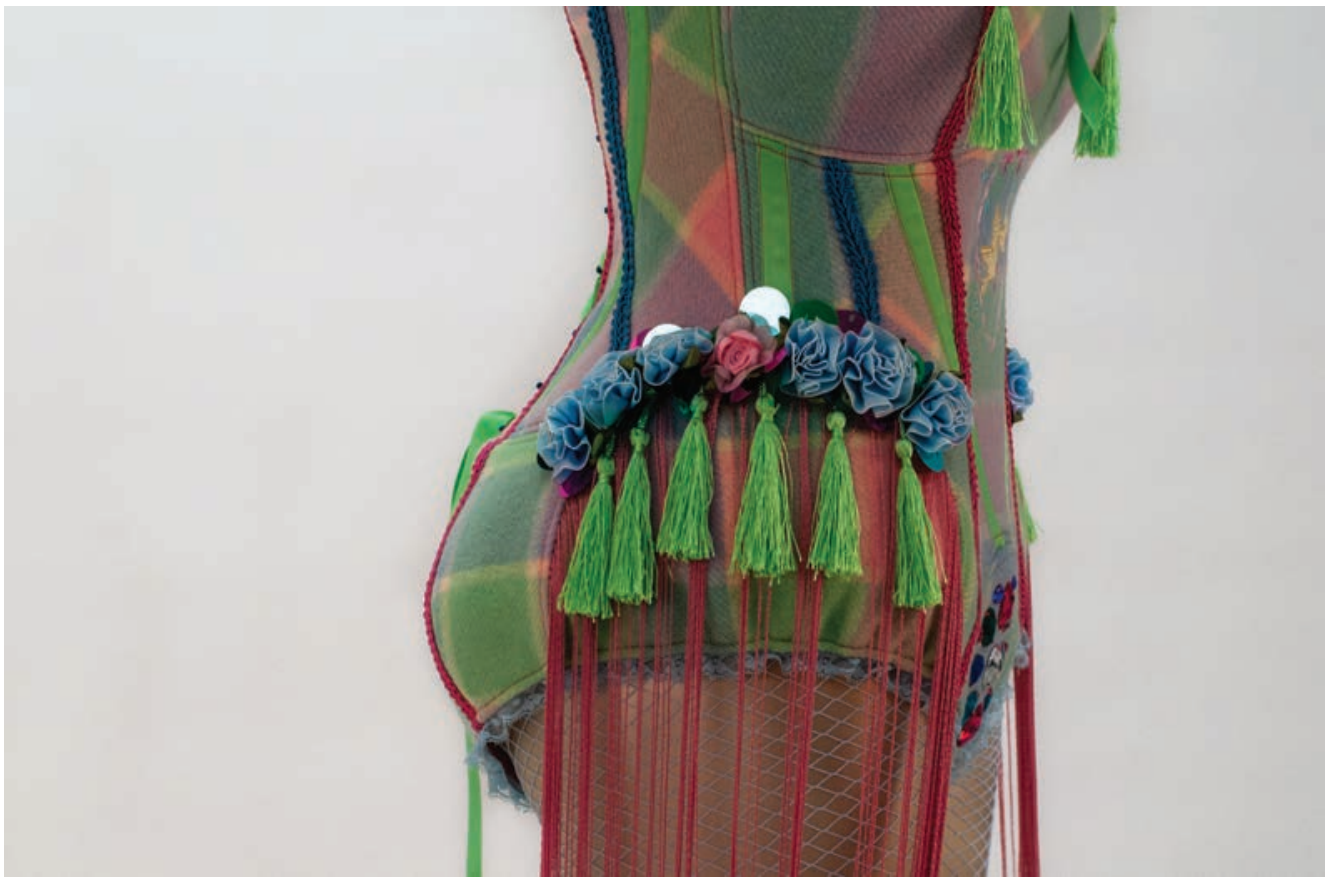




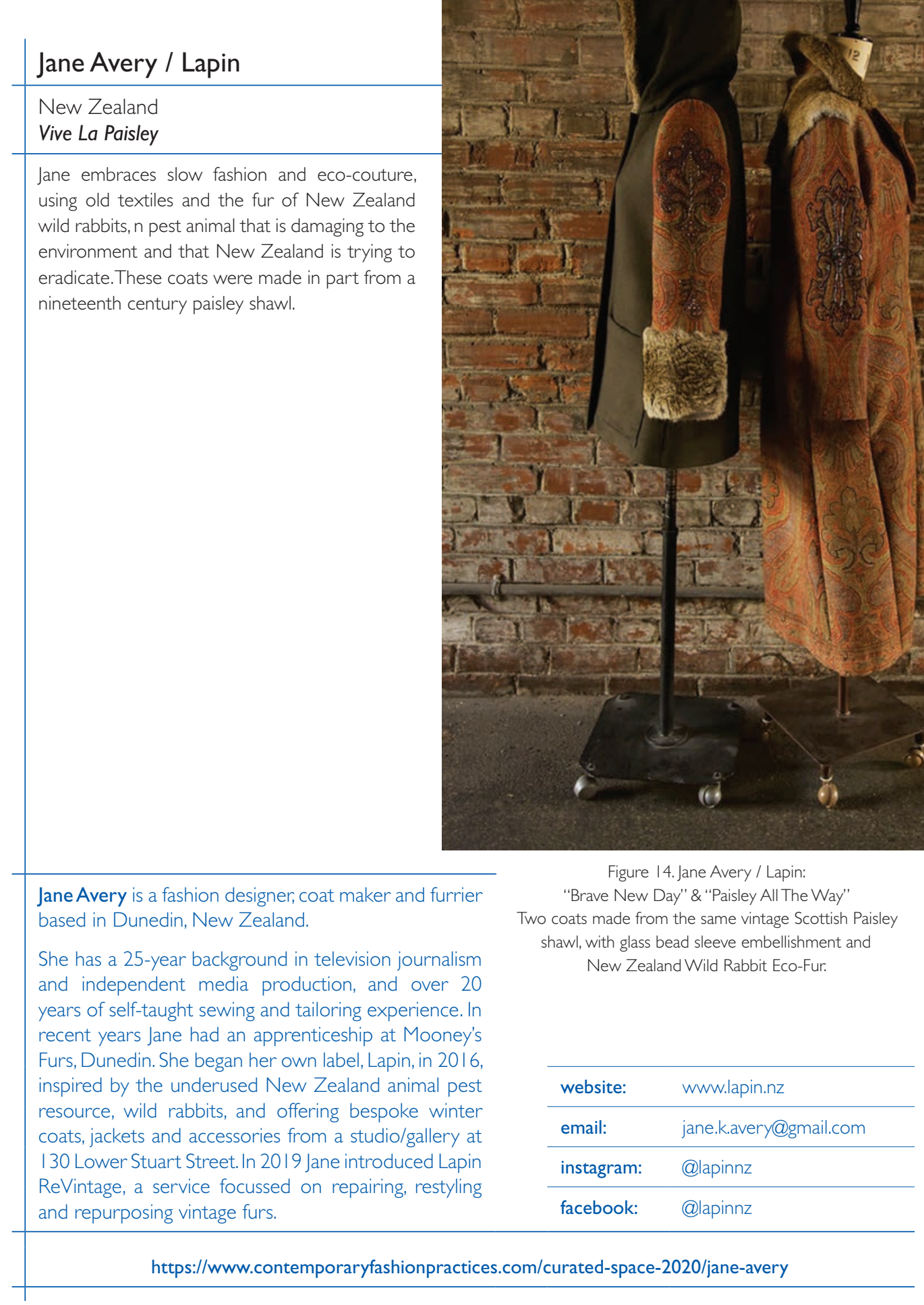




\section{II}

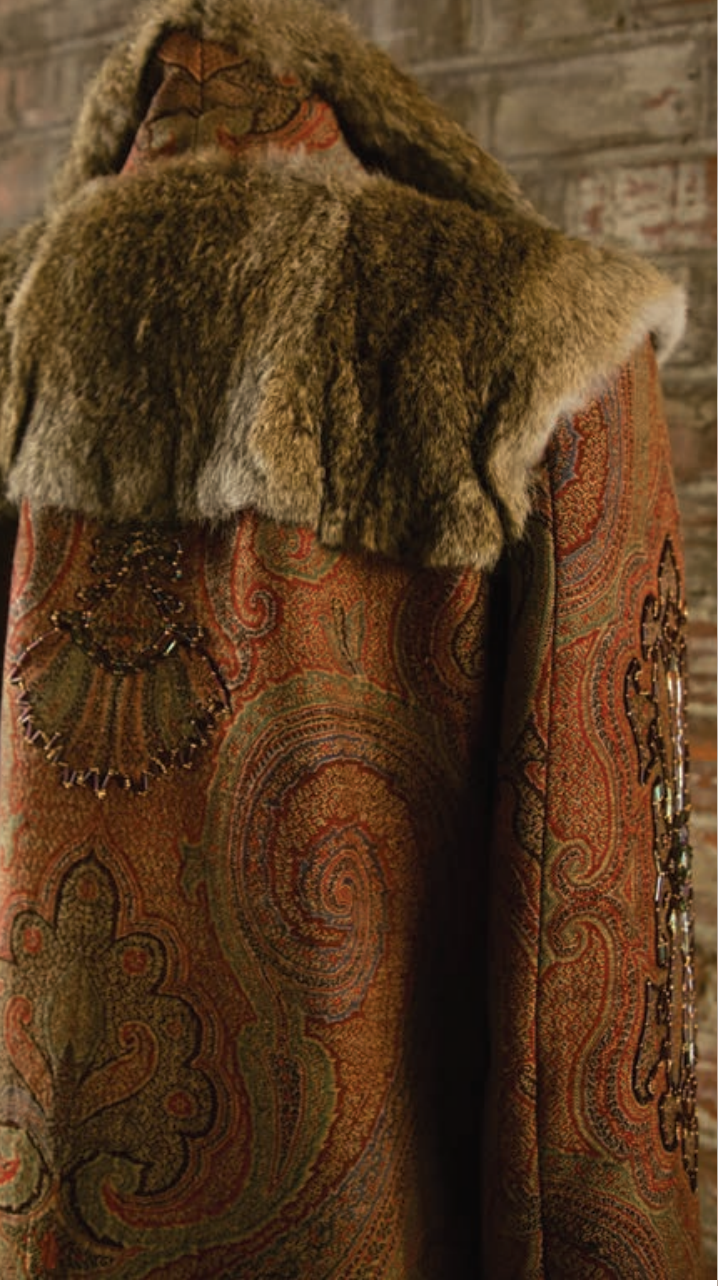

Figure 15. Jane Avery / Lapin: "Brave New Day" \& "Paisley All The Way"

Two coats made from the same vintage Scottish Paisley shawl, with glass bead sleeve embellishment and New Zealand Wild Rabbit Eco-Fur.

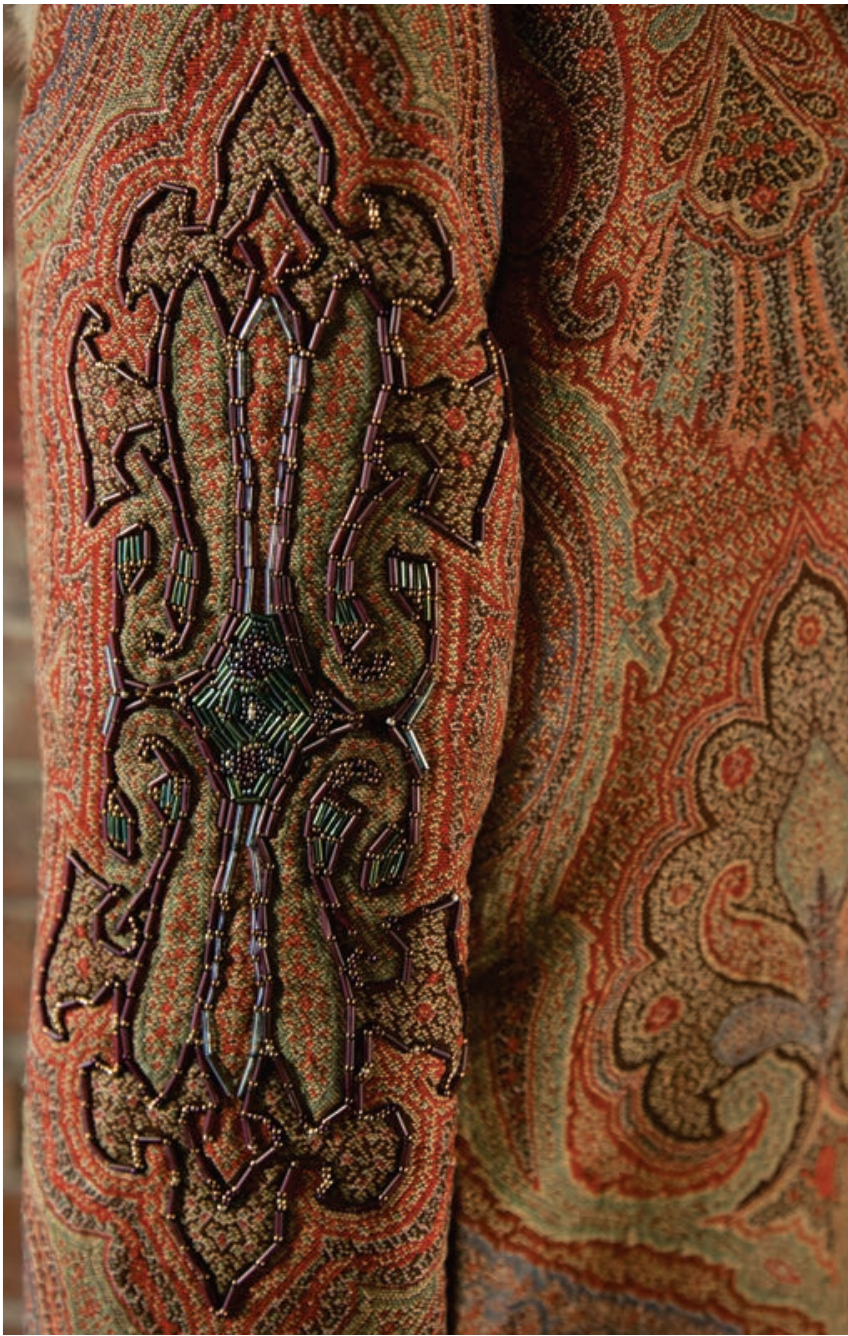

Figure 16. Jane Avery / Lapin:

"Paisley All The Way"

Sleeve detail with glass beads both repurposed and new. 


\section{Jun Nakamura}

Japan / UK

Shibori in the Shape Making Strategy

Jun uses shibori tying techniques with careful placement to help create a garment's shape or form, rather than creating all-over patterns or designs. He often works with already printed fabric where the shibori interrupts the flow of the print, as well as giving the fabric the elasticity to provide shape over the body.

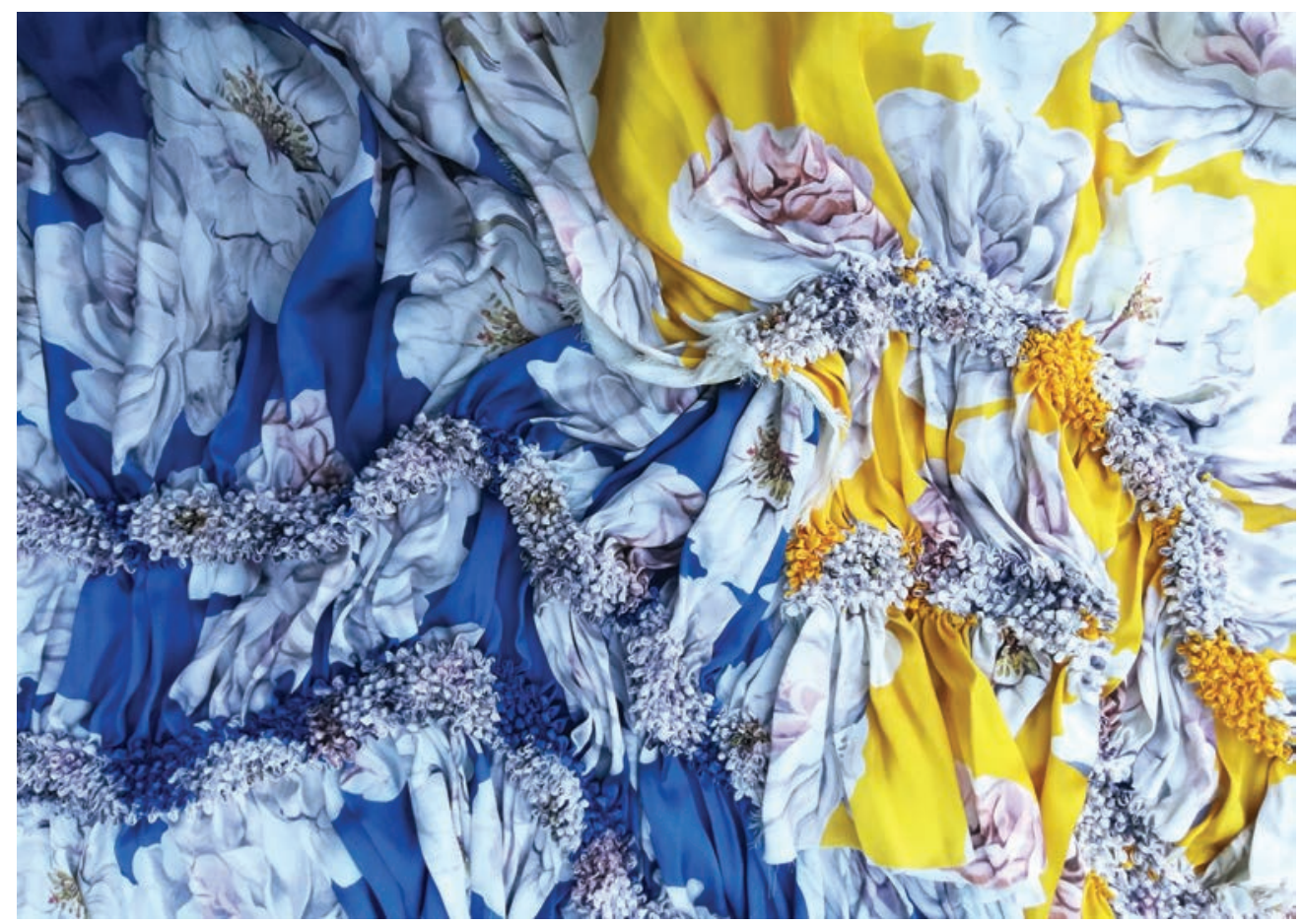

Figure 17. Signature style Shibori on surrealistic flower prints. Shibori in the Shape Making Strategy. Jun Nakamura.

Jun Nakamura is a founder of JU-NNA. He studied MA Fashion Design Womenswear at Istituto Marangoni London after working in the Japanese fashion industry. Jun's first collection was nominated for both Mittelmoda The Fashion Award and a Fashion Scout Merit Award in 2018 while he was at university and featured in many magazines and media articles. After graduation, Jun was granted an Exceptional Talent Promise visa with an endorsement from the British Fashion Council. He started JU-NNA in 2019.

\begin{tabular}{ll} 
website: & https://www.ju-nna.com \\
\hline email: & info@ju-nna.com \\
\hline instagram: & https://www.instagram.com/ju_nna_ \\
\hline facebook: & $\begin{array}{l}\text { https://www.facebook.com/ } \\
\text { junnashibori/ }\end{array}$ \\
\hline
\end{tabular}

https:/www.contemporaryfashionpractices.com/curated-space-2020/jun-nakamura 


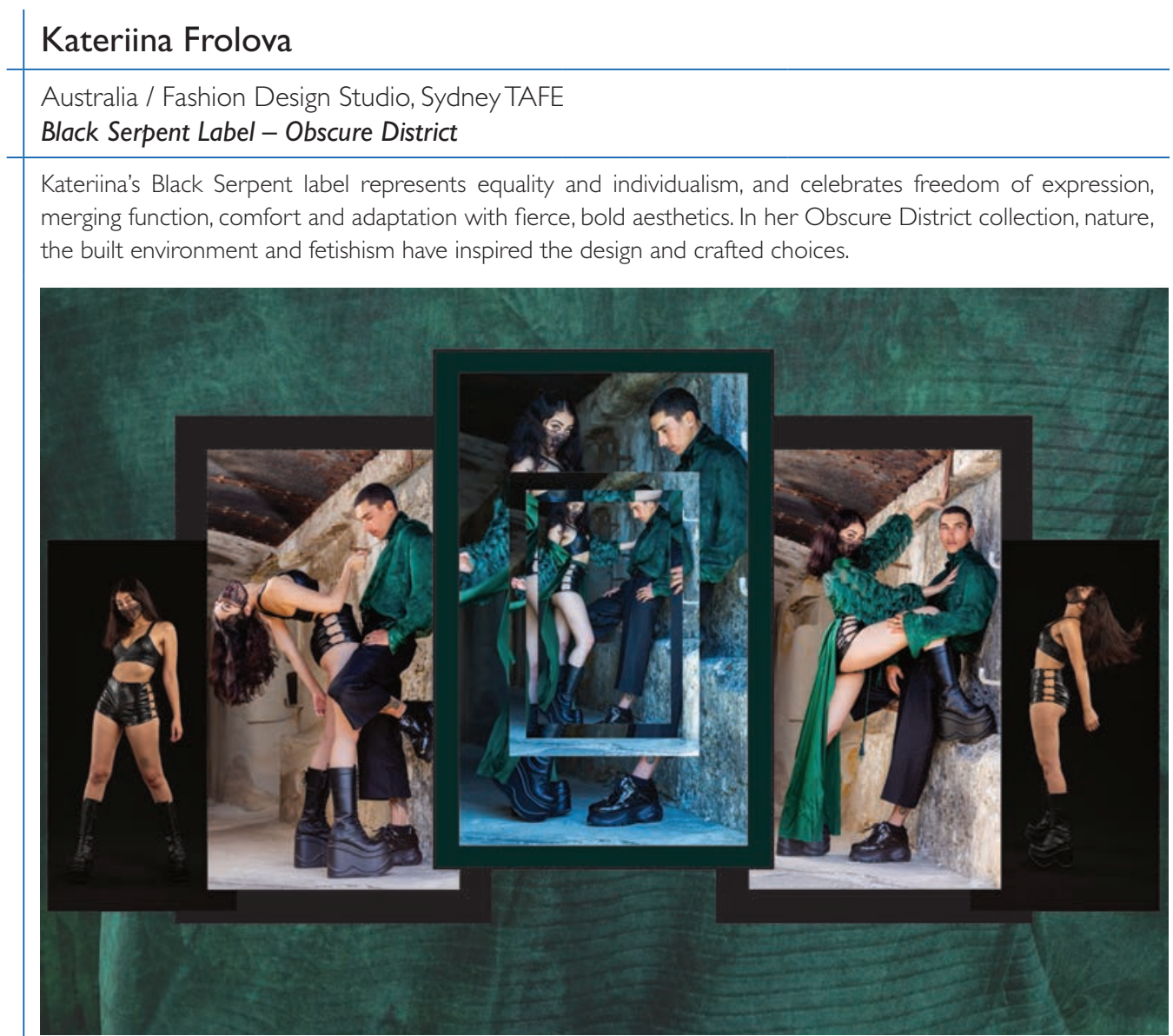

Figure 18. Black Serpent, "Obscure District", Kateriina Frolova.

Kateriina Frolova recently graduated from FDS TAFE with a Bachelor of Fashion Design, and created Black Serpent as her final coursework project. In creating her fashion label, she drew a lot of inspiration from her personal experiences. Her graduate collection, Obscure District, is the result of her curiosity and engagement in alternative cultural movements and merges those influences, creating her own fashion language and a unique means of self-expression. Originally from a small town called Võru in Estonia, Kateriina moved to Australia in 2013 after two years of travelling around Europe, and is now based in Sydney. 


\begin{tabular}{|c|c|c|}
\hline \multicolumn{3}{|l|}{ Kirsten Scott and Karen Spurgin } \\
\hline \multicolumn{3}{|l|}{$\begin{array}{l}\text { UK and Uganda/Instituto Marangoni } \\
\text { Fashion from Trees:A Collaborative Critical Practice }\end{array}$} \\
\hline $\begin{array}{l}\text { Kirsten and Karen work in a cross-disciplinary, cross- } \\
\text { continental and collaborative fashion and textiles } \\
\text { practice which draws upon conceptual frameworks } \\
\text { more commonly associated with science, health, } \\
\text { architecture and engineering, including natural } \\
\text { medicine (through Ayurvastra), biodesign, biophilia } \\
\text { and biomechanics. Their practice uses slow } \\
\text { neocrafting techniques to enhance the wellbeing } \\
\text { of the makers and wearers of eco-utopian fashion } \\
\text { garments. These garments are made from Ugandan } \\
\text { barkcloth - a fabric formed from trees. }\end{array}$ & & \\
\hline \multicolumn{3}{|l|}{$\begin{array}{r}\text { Figure 19. Barkcloth coat. } \\
\text { Fashion from trees. } \\
\text { Kirsten Scott and } \\
\text { Karen Spurgin. }\end{array}$} \\
\hline \multirow[b]{2}{*}{$\begin{array}{l}\text { Kirsten Scott is programme leader for MA Fashion } \\
\text { Design Womenswear and MA Luxury Accessory } \\
\text { Design at Istituto Marangoni in London. Her practice- } \\
\text { based PhD in constructed textiles, at the Royal College } \\
\text { of Art, involved collaboration with women in Uganda } \\
\text { to develop alternative, ethical and sustainable materials } \\
\text { and accessories. Kirsten's research questions the } \\
\text { meaning and value of the handmade, and interrogates } \\
\text { the paradigm of luxury. Her focus as a researcher has } \\
\text { become increasingly holistic and multi-disciplinary. }\end{array}$} & website: & www.kirstenscott.org \\
\hline & instagram: & $\begin{array}{l}\text { https://www.instagram.com/ } \\
\text { kirstenscottz/ } \\
\text { \#barkclothresearchnetwork } \\
\text { \#kirstenscottz } \\
\text { \#fabricfromtrees } \\
\text { \#barkcloth }\end{array}$ \\
\hline \multirow[b]{2}{*}{$\begin{array}{l}\text { Karen Spurgin is a senior lecturer at Istituto Marangoni } \\
\text { London, teaching fashion design and fashion business } \\
\text { students. She co-founded and works as part of a design } \\
\text { collective, ao textiles, a project-based consultancy } \\
\text { specialising in the research and development of } \\
\text { sustainable textiles. Her research into surface } \\
\text { techniques and finishes includes revisiting natural } \\
\text { dyeing techniques in the twenty-first century. All ao } \\
\text { projects put environmentally responsible design at the } \\
\text { heart of production methods. }\end{array}$} & website: & http://www.aotextiles.com \\
\hline & instagram: & $\begin{array}{l}\text { https://www.instagram.com/ } \\
\text { ao_textiles/ } \\
\text { \#barkclothresearchnetwork } \\
\text { \#ao_textiles } \\
\text { \#fabricfromtrees } \\
\text { \#barkcloth }\end{array}$ \\
\hline
\end{tabular}

https://www.contemporaryfashionpractices.com/curated-space-2020/kirsten-scott-karen-spurgin 


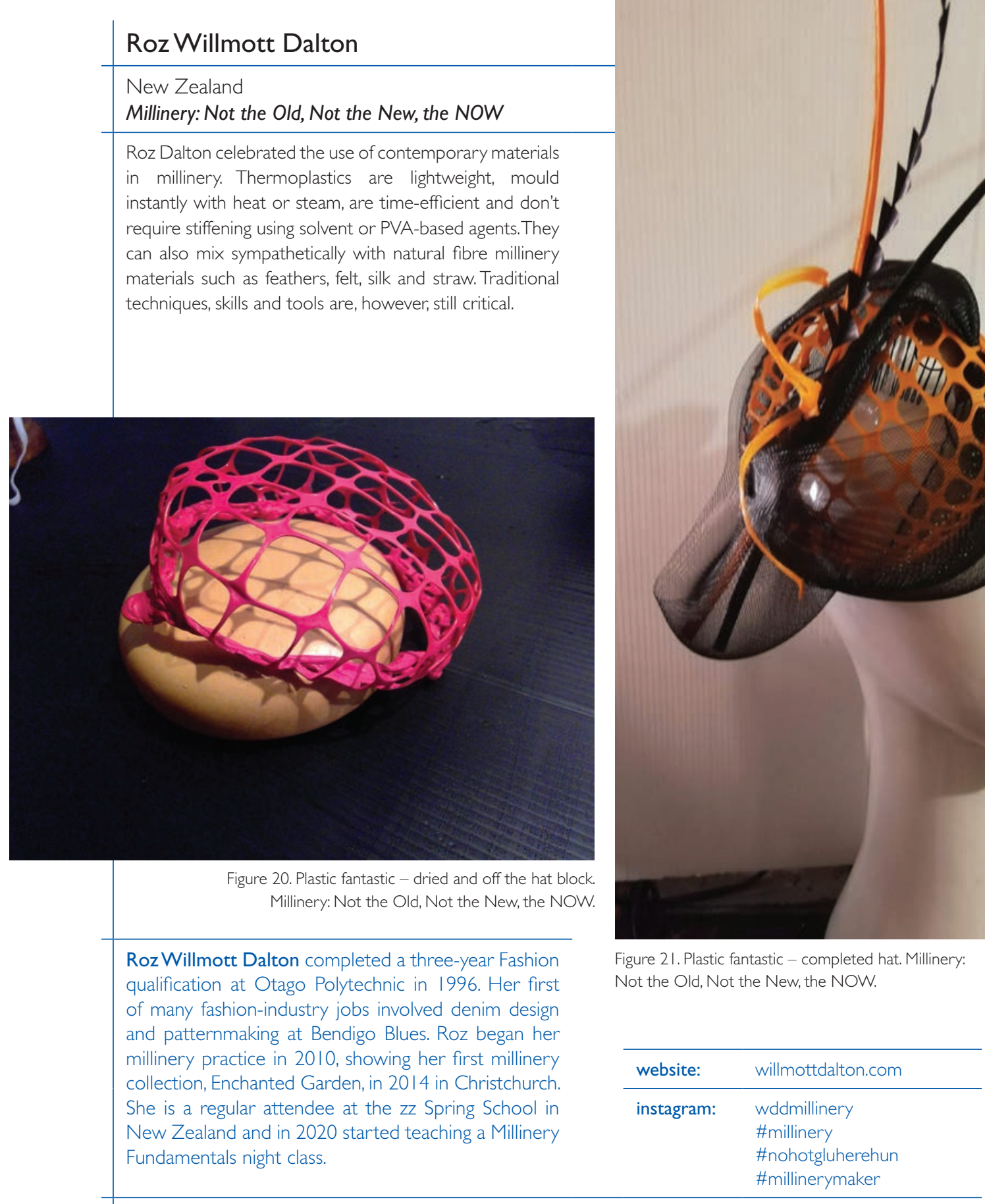

https://www.contemporaryfashionpractices.com/curated-space-2020/roz-willmott-dalton 


\section{Lisa McEwan}

New Zealand / Auckland University of Technology

Hear No Evil, See No Evil, Wear No Evil

Lisa McEwan aimed to promote discussion of the use of non-human animals for food, entertainment and clothing. One digitally printed garment, and MEAT, a suite of costumes for a contemporary dance work, challenged the role of domesticated species products in the fashion industry, and prompted examination of the surrounding ethical and environmental issues.

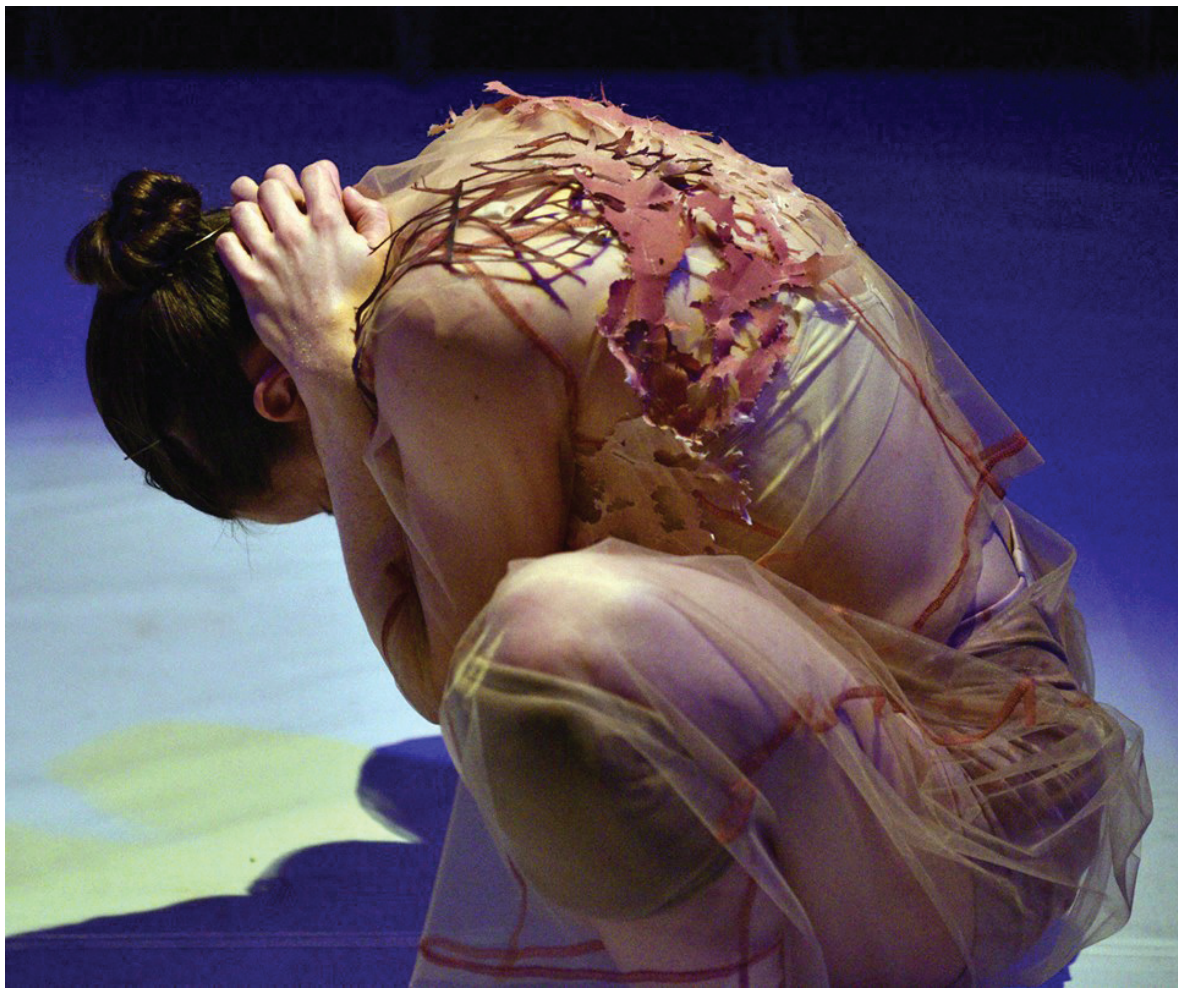

Lisa McEwan is a senior lecturer in Fashion Design and Design for Sustainability at Auckland University of Technology (AUT), New Zealand. She completed her Master of Design at AUT in 2012 and has more than 25 years' experience in the fashion industry. Her current practiceled research uses clothing design as a vehicle for social and political commentary. La Bombe (1988), designed as a protest against French nuclear tests in the Pacific, is in the collections of Te Papa Tongarewa, Museum of New Zealand.
Figure 22. MEAT dance costume \#3. Hear no evil, see no evil, wear no evil. Lisa McEwan.

email:

lisa.mcewan@aut.ac.nz

https://www.contemporaryfashionpractices.com/curated-space-2020/lisa-mcewan 


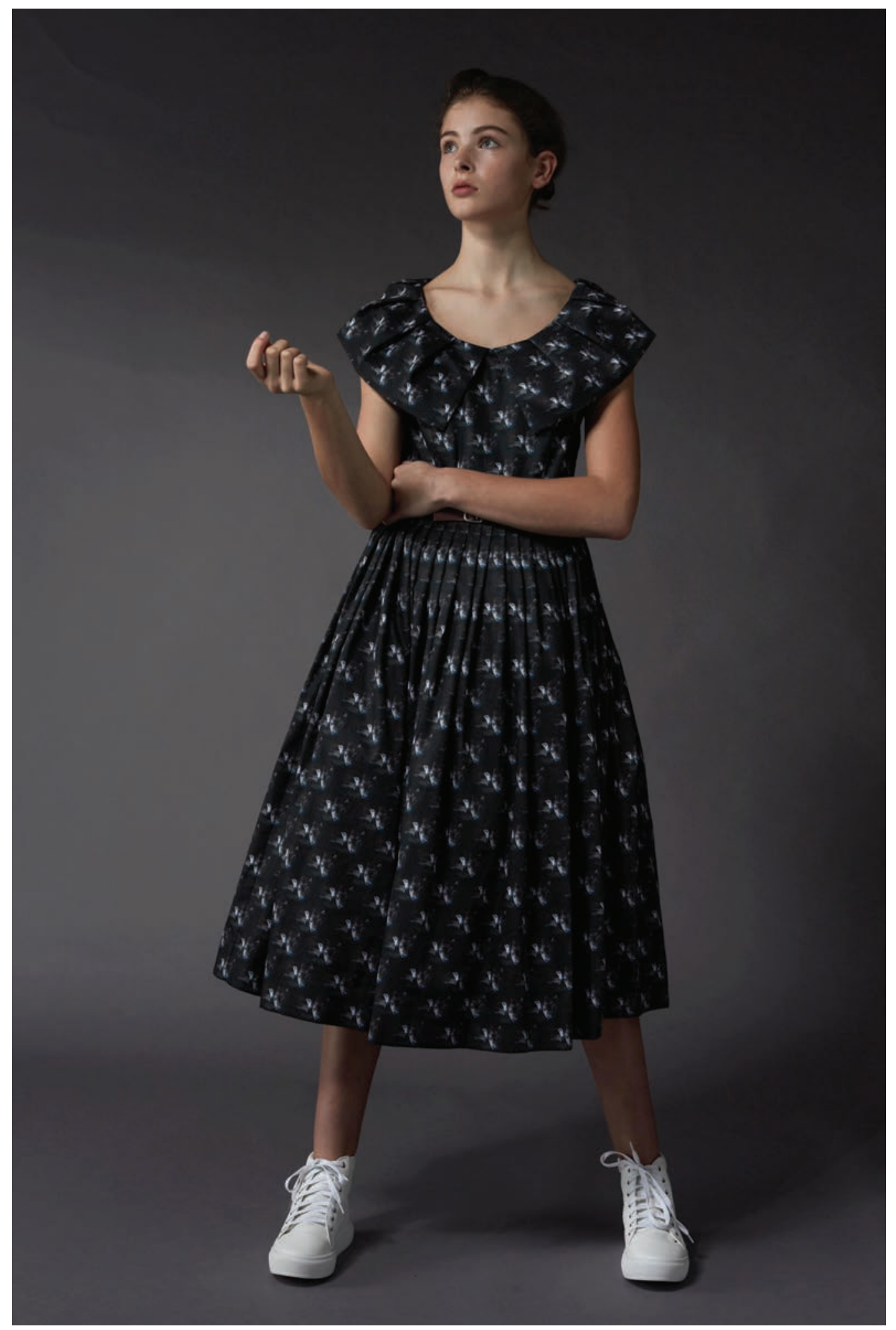

Figure 23. Costume for a Noble Discontent \#2.

Hear no evil, see no evil, wear no evil. Lisa McEwan. 


\section{Noorin Khamisani}

United Arab Emirates / Dubai Institute for Design and Innovation

Fashion Design for Multiple Lives

Noorin posed the question: If in the future all our garments need to be shared, rented or have many owners, how will that change the design process and the garments created? Her prototypes each took a different approach to the idea of multiple lives - size adaptability, reversibility and variability - to create a circular alternative to current fashion practice.
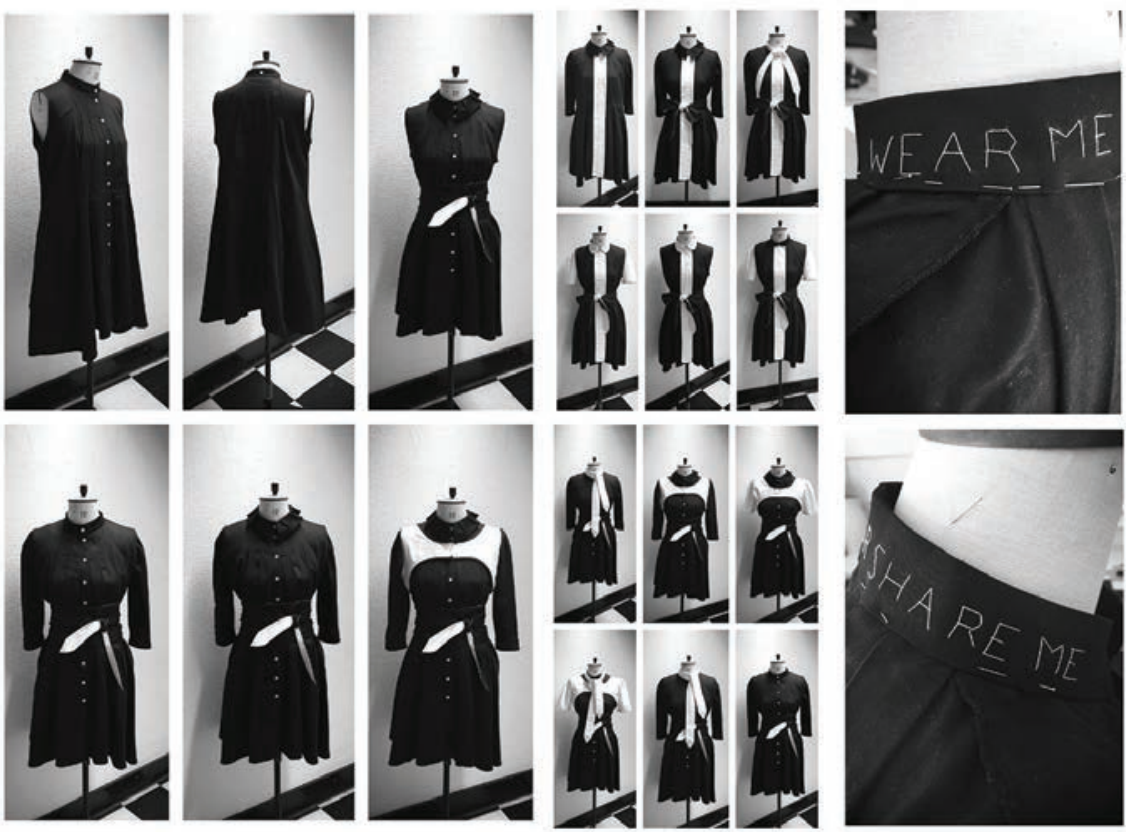

Figure 24. Fashion Design for Multiple Lives. Noorin Khamisani. "Wear me or share me” Multi shirt dress 120 looks.

Noorin Khamisani is a London-born fashion designer, researcher and educator based in the United Arab Emirates. Her work focusses on fashion design for sustainability, informed by a decade of her own professional practice. Her current research explores how fashion education needs to evolve to ensure that students have the skills they need in a fastchanging industry. 


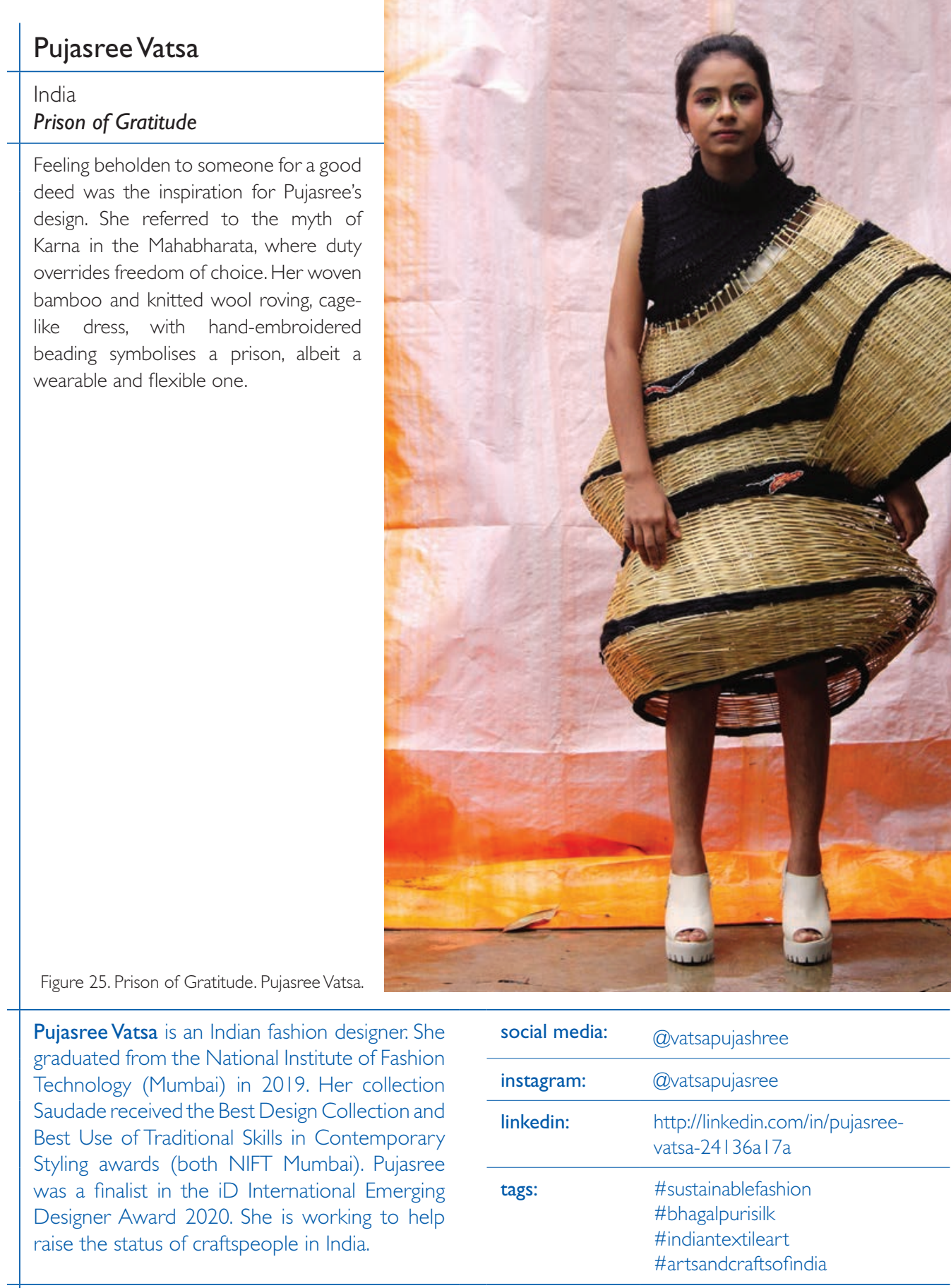

https://www.contemporaryfashionpractices.com/curated-space-2020/pujasree-vatsa 


\section{Pam McKinlay}

New Zealand / Otago Polytechnic

Ice is Cool

Pam is a weaver and textile artist with a background in applied science and the history of art. The works she creates are made predominantly in collaboration with scientists. Wearing textiles with an embodied story is an ideal way to communicate climate imperatives in digestible chunks. The scarves and shawls she creates have intricate surface detail that invites queries as to how they were made and why.

Cubic ice crystal motifs are woven into her scarf Ice is Cool, using wool/silk and fine rayon yarns. The motifs fragment towards the end of the scarf, graphically representing the effects of climate change on the cryosphere, source of earth's water. Melt-stream events are incorporated into two other scarves, using the Tasman Glacier as inspiration.

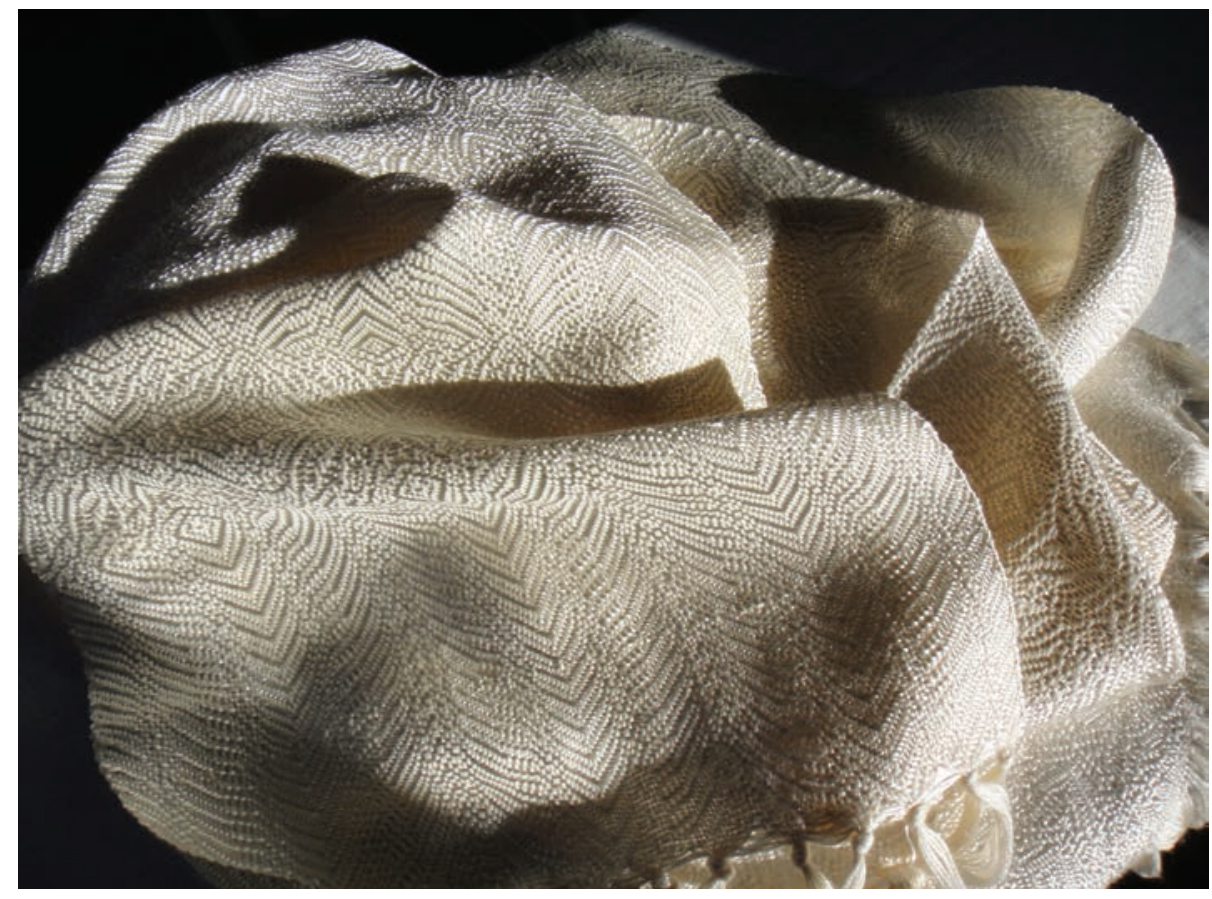

Pam McKinlay works part-time for the Dunedin School of Art and the Research Office at Otago Polytechnic,

Figures $26,27 \& 28$. Ice is Cool. Pam McKinlay.

in media, publications and special projects. She has been a long-time participant in Otago Polytechnic's Art + Science series and has been the co-ordinator for the last three projects. She majored in textile science, clothing design, art history and history at the University of Otago, and later studied tikanga Maori, mauri ora and project management.

social media:@Pam McKinlay

https://www.contemporaryfashionpractices.com/curated-space-2020/pam-mckinlay 


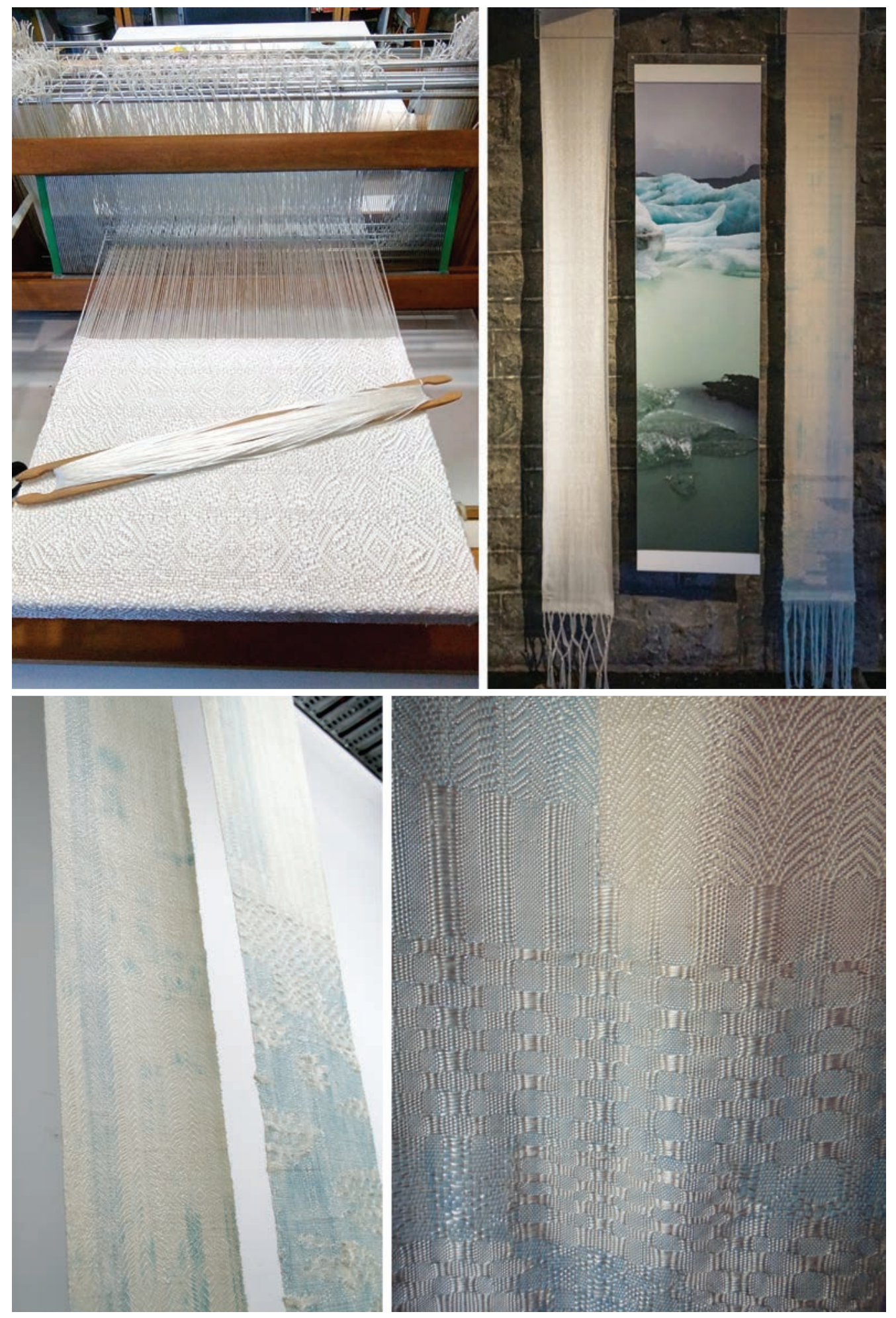




\section{Rayed Barkat}

Bangladesh / BGMEA University of Fashion and Technology

\section{Back to the Roots}

Using fabrics and techniques indigenous to Bangladesh, such as khadi, kantha and indigo dyeing, and foregrounding the use of jute, Rayed creates garments that highlight the materials and processes involved in their making.
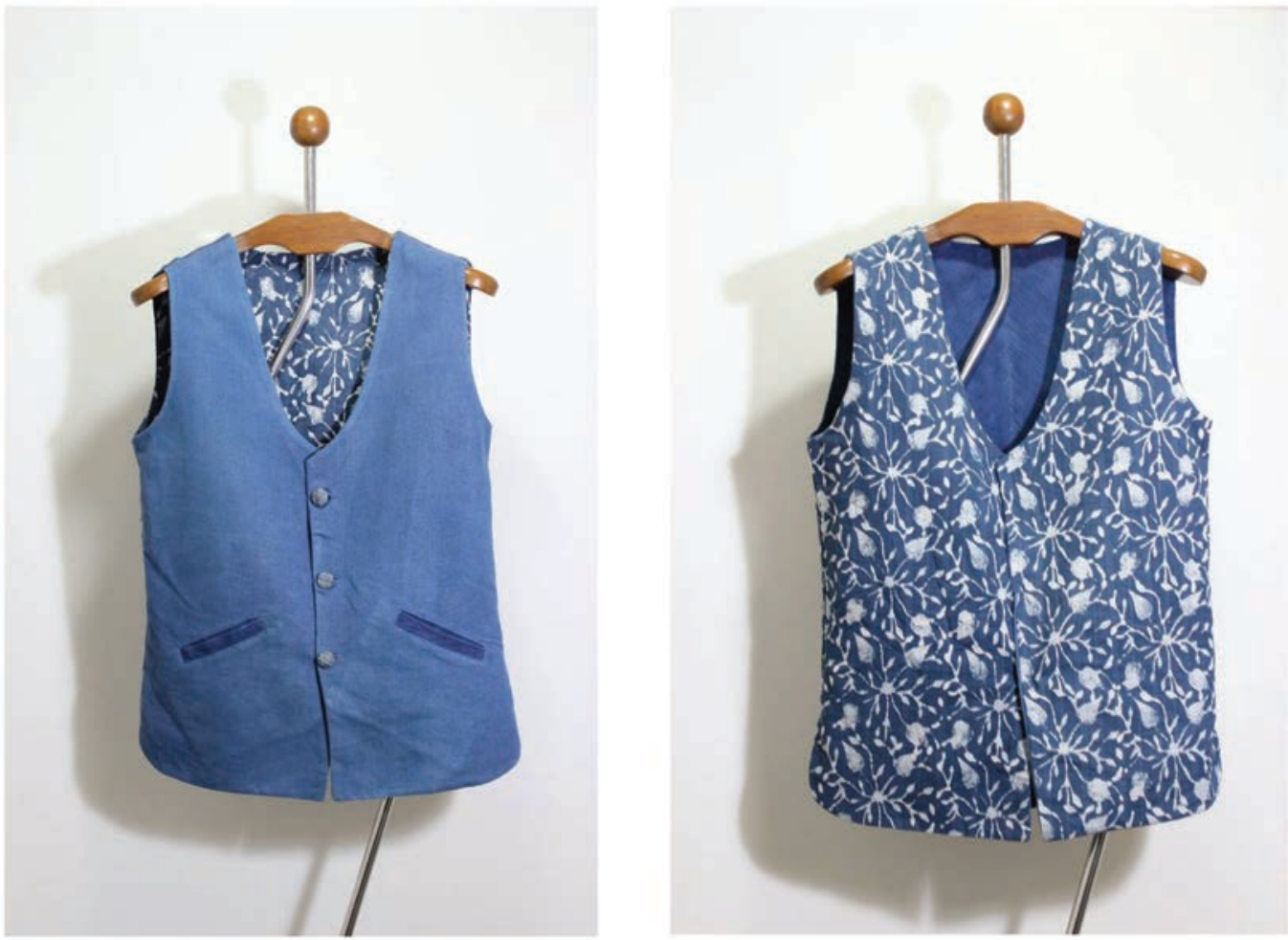

Figure 29. BACKTOTHE ROOTS. Rayed Barkat.

Rayed Barkat is a designer and academic from BGMEA University of Fashion and Technology, Dhaka, Bangladesh, where he has been engaged in designing, teaching and research for the past eight years. Concern about sustainability in the fashion industry has led to his participation in international collaborative projects such as Local-International in 2016 and the Copenhagen Fashion Summit in 2017. 


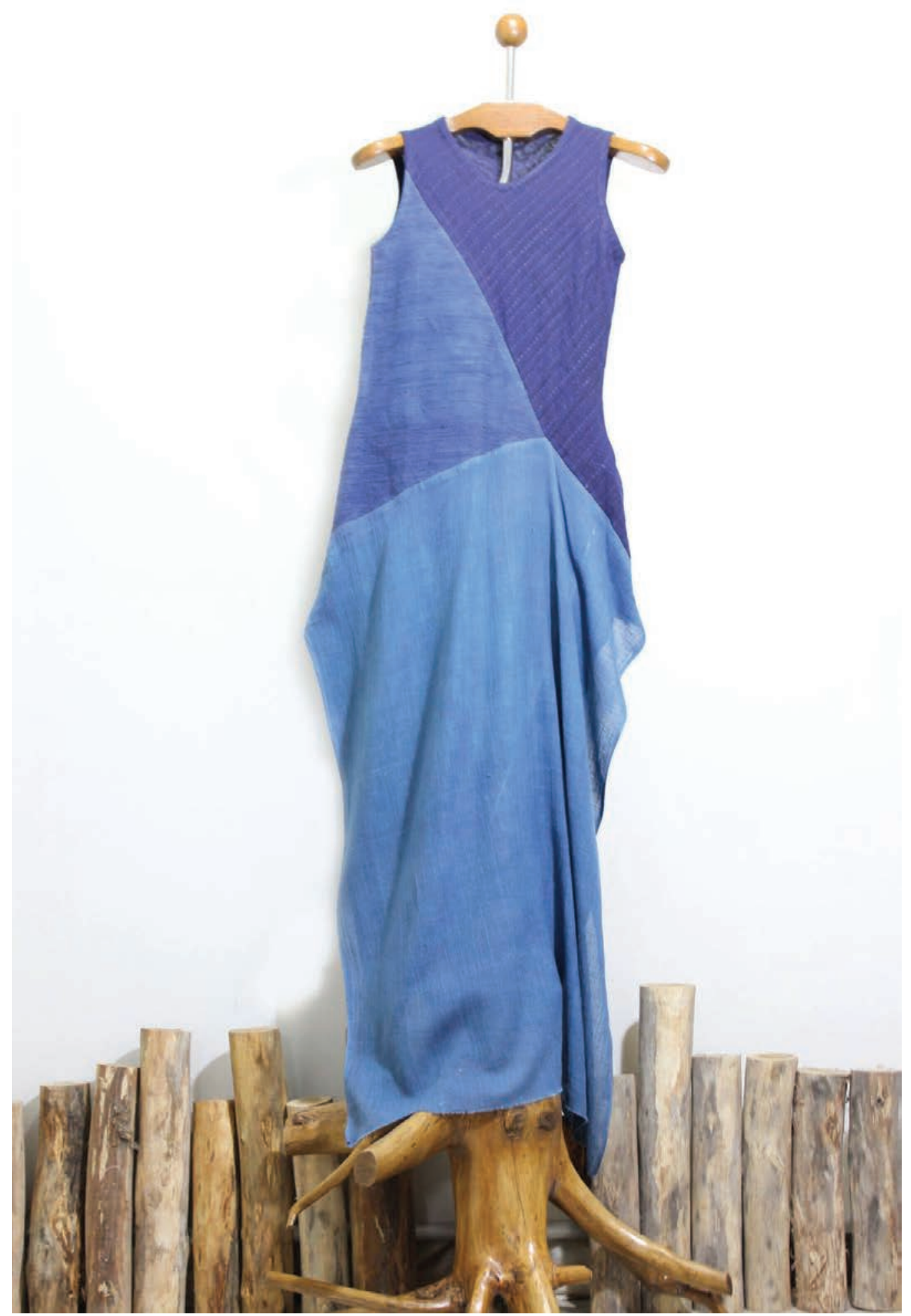

Figure 30. BACKTOTHE ROOTS. Rayed Barkat. 


\section{Rekha Shailaj}

New Zealand / Otago Polytechnic Our Ephemeral Worlds: Fashion and Covid-1 9 reality

The maker and the materials share a symbiotic relationship. The choice of paper as a material to create fashion design objects arose because of the Covid-19 lockdowns imposed in 2020. The response to restriction facilitated creativity in the "Third Space," which is distinguished by a lack of normalcy. This body of work encourages the act of viewing a fashion artefact, in contrast to wearing it. It directs us to engage in a discourse about the morphing of the fashion experience itself.

Figure 31. Our Ephemeral Worlds: Conversations Paper.

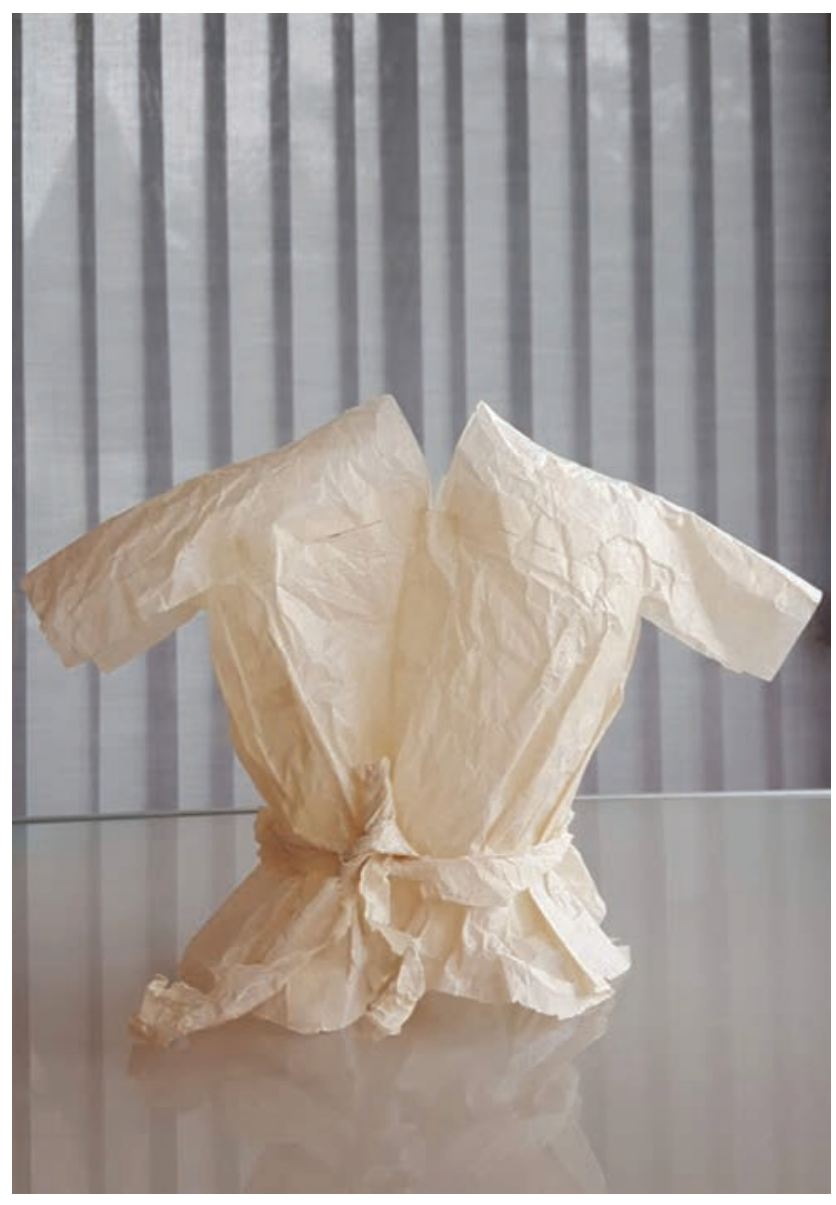

Rekha Rana Shailaj is a senior lecturer at the School of Design, Otago Polytechnic, where she teaches in the Fashion programme. Rekha has a Bachelor of Design email: rekha.rana@op.ac.nz (Fashion) from Otago Polytechnic and a Master of Fine Arts (Design) with distinction from the Dunedin School of Art, Otago Polytechnic. Rekha practices design in a multicultural environment. Her current research focus is on working with traditional clothing from India, where she was born and raised, and extending construction methods to create near-zero waste fashion outcomes.

Figure 32. An Object: process paper toiles. https://www.contemporaryfashionpractices.com/curated-space-2020/rekha-shailaj 



\section{Rokaiya Ahmed Purna}

Bangladesh / BGMEA University of Fashion and Technology

Urban Tribal - RAP

In the belief that design can be an effective tool for progress in society, Rokaiya Purna investigated its role in supporting an artisanal community through respect for the environment, ecosystems and local communities. Handloom-woven textiles, the empowerment of women and girls, and environmentally responsible production and consumption processes are central to her practice.
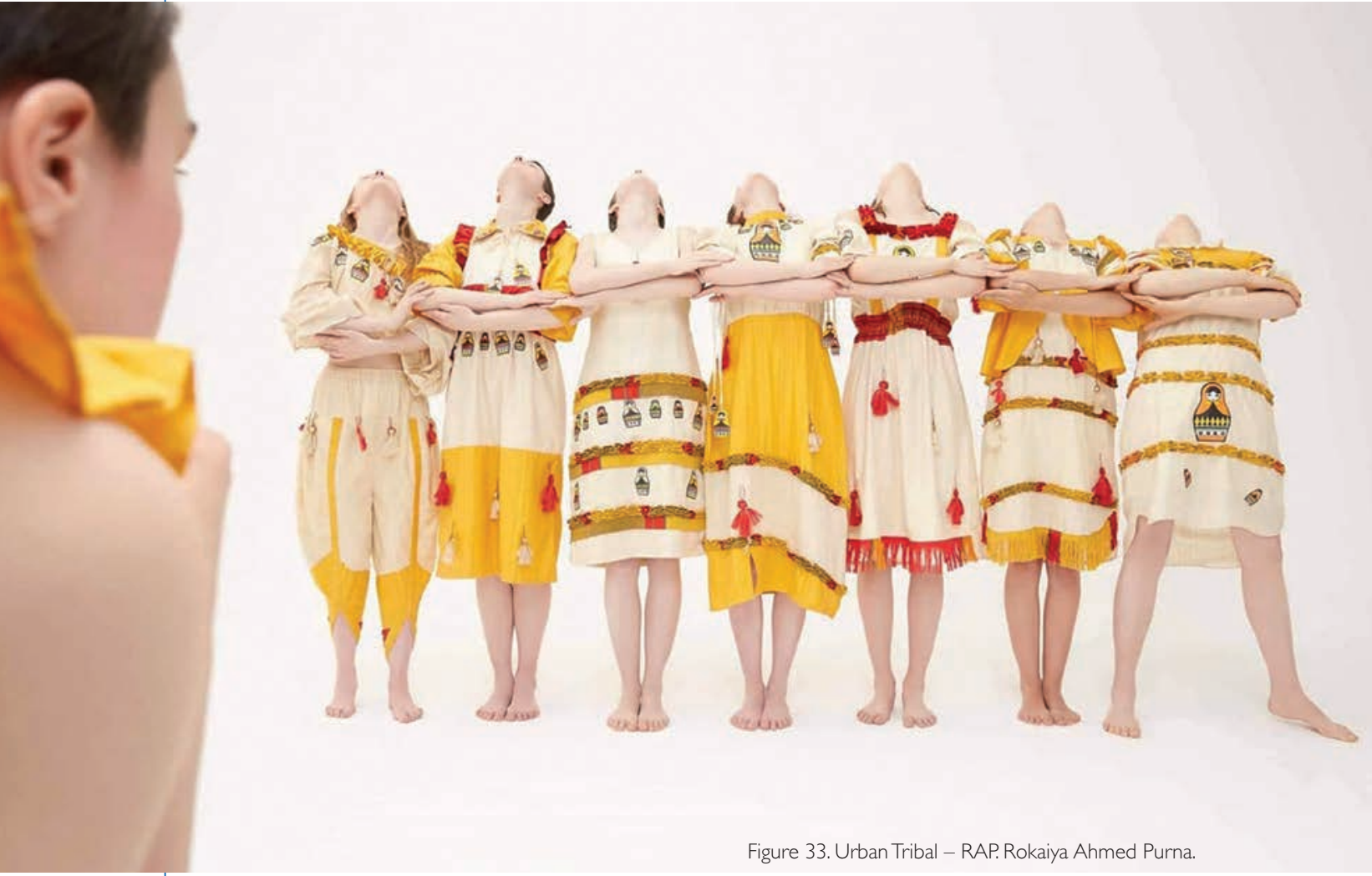

Figure 33. Urban Tribal - RAP. Rokaiya Ahmed Purna.

Rokaiya Ahmed Purna is a Bangladeshi fashion designer who graduated in 2018 . She represents the culture and heritage of Bangladesh in the global fashion arena. She fuses traditional Bangladeshi textile culture with the country's creative economic and sustainability goals into her couture, while empowering women and girls. She aims to become one of the country's largest high-street designers and young entrepreneurs.

\begin{tabular}{ll} 
website: & rokaiyaahmedpurna.com \\
\hline instagram: & rokaiyaahmedpurna \\
\hline facebook: & rokaiyaahmedpurna \\
\hline linkedin: & rokaiya-ahmed-purna \\
\hline twitter: & rap_purna \\
\hline YouTube: & Rokaiya Ahmed Purna channel
\end{tabular}

https://www.contemporaryfashionpractices.com/curated-space-2020/rokaiya-ahmed-purna 


\section{Simon Swale}

New Zealand / Otago Polytechnic

\section{Urban Garment}

Simon creates wearable objects that respond to urban space, place and non-place, and that critique the global economy and human globalisation. His piece for this exhibition is a textile recreation of a banana box that can, unlike the cardboard original, be draped and worn on the human body in a variety of ways.

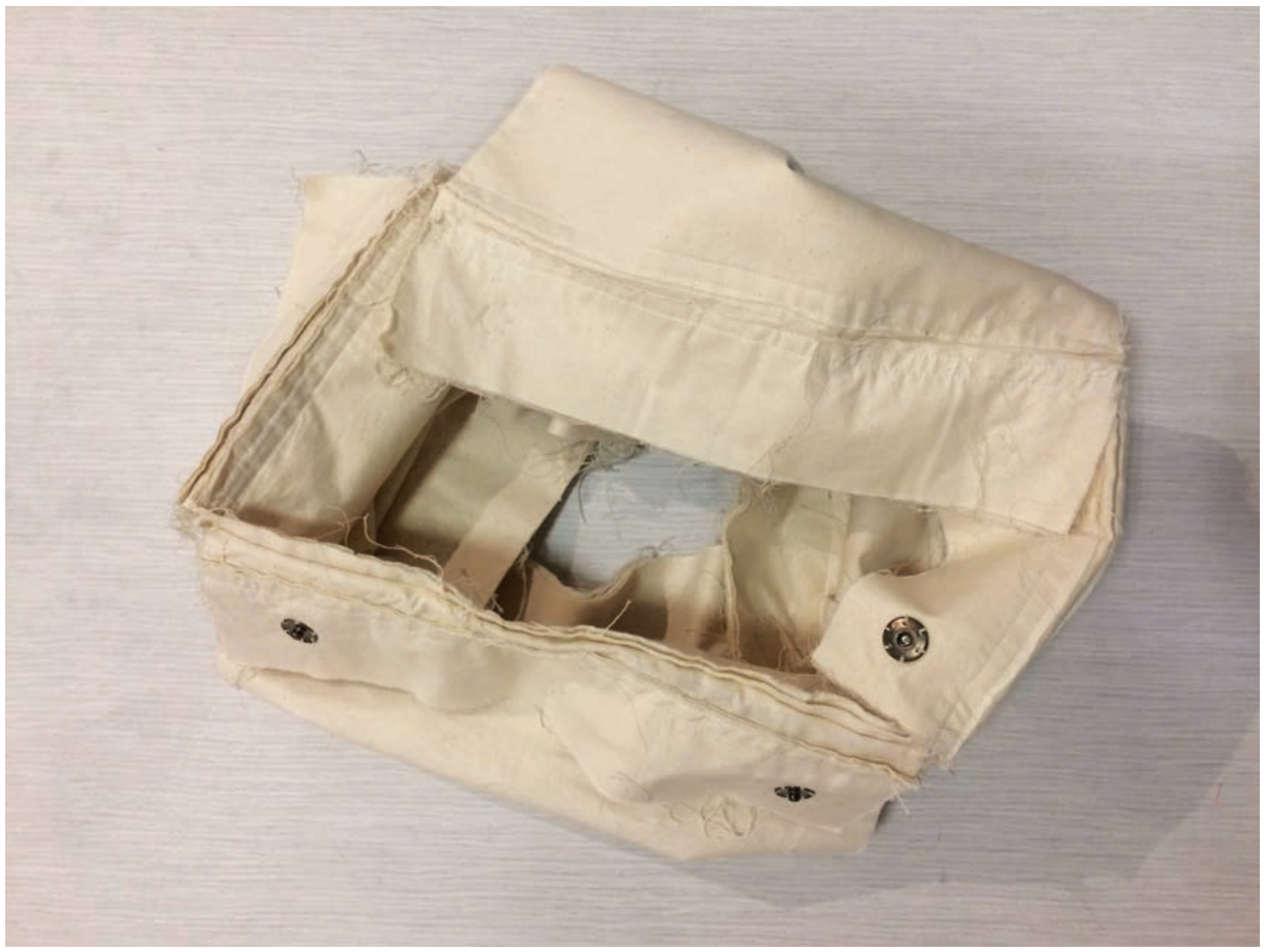

Figure 36. Urban Garment.

Simon Swale is an artist, designer and senior instagram: $\quad$ simon.marcus.swale lecturer teaching in the Fashion program at the School of Design, Otago Polytechnic. He completed a Master in Fine Arts at the Dunedin School of Art in 2020, and is a participant in the Handshake mentorship program, mentored by German artist Gabi Schillig. 


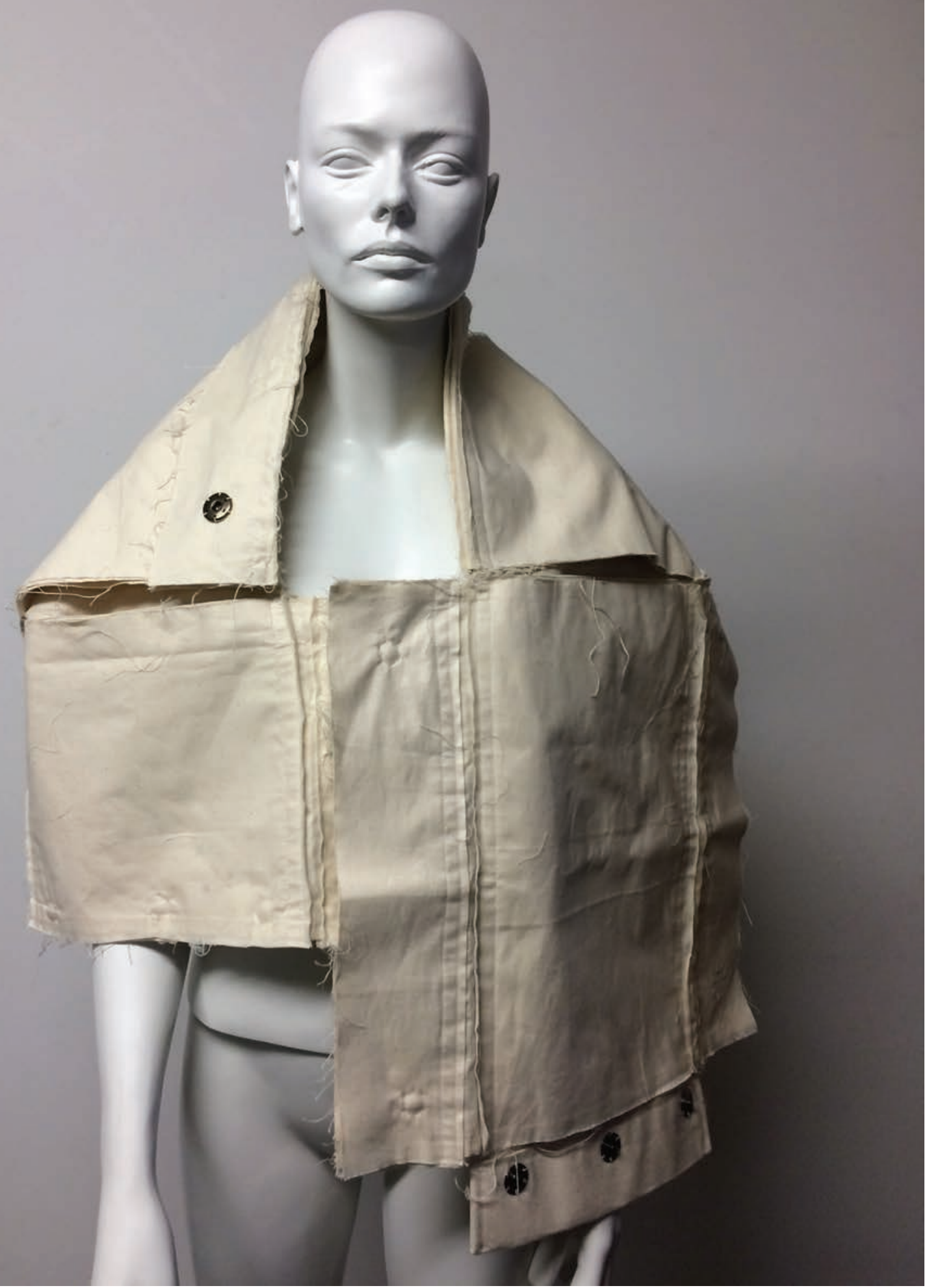

Figure 37. Urban Garment. 


\section{Leica Johnson}

New Zealand / Auckland University of Technology An exploration of the ambiguity and significance of everyday affordable sustainable clothing

Since new sustainable fashion is often beyond the budgets of many consumers, Leica has designed and made lower-cost clothes, repurposing materials and using her own set of limitations to keep costs down. She has concentrated on a small range of garment forms that can be worn together, with interchangeable accessories such as waistcoats, collars, pockets and hoods.

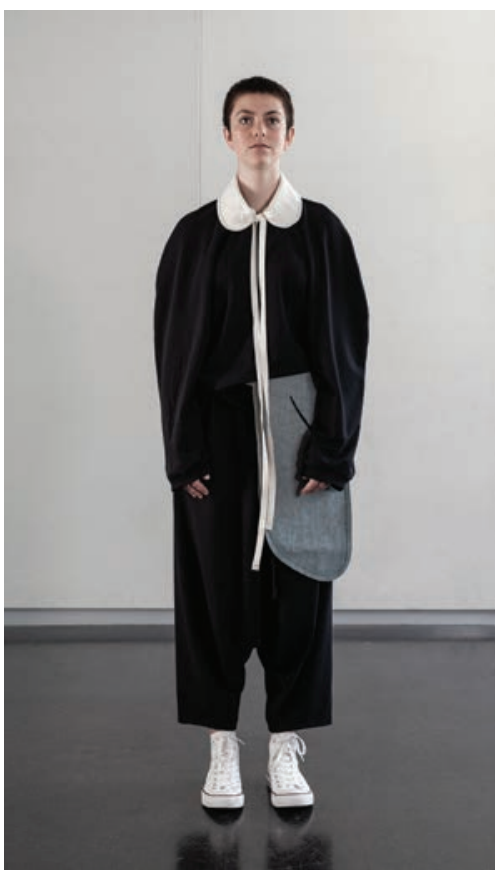

Figure 38. Expressive. Item 9. Sweatshirt, worn with Item I I. Breeched sweatpants. Accessorised with Item 18. Collar, and Item 4 Big pocket bum bag.

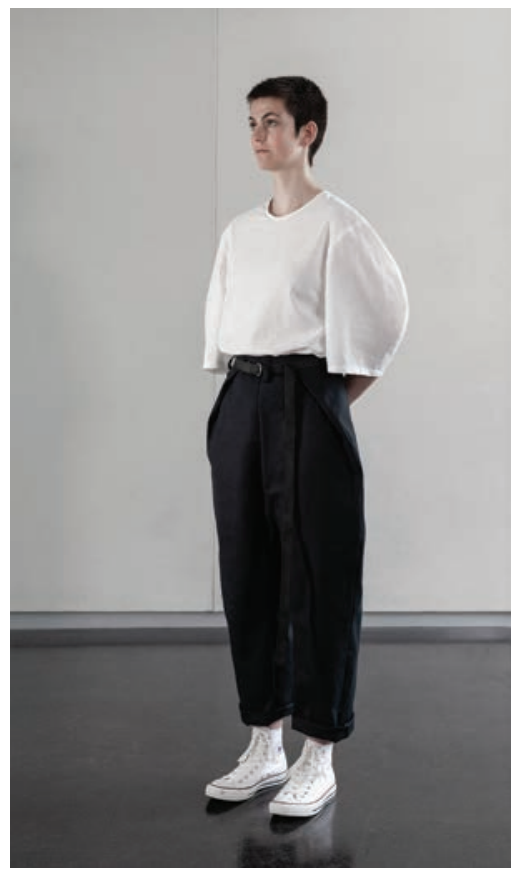

Figure 39. Conforming. Item 17.

Top, worn with Item 7. Front fold pants.

Leica Johnson is a lecturer in the Bachelor of Fashion at the School of Art and Design, Auckland University of Technology, New Zealand.

The project includes excerpts from a thesis submitted to Auckland University of Technology in partial fulfilment of the requirements for the Degree of Master of Design: Leica Johnson, A remembering of culture and community: An exploration of the ambiguity and significance of everyday affordable sustainable clothing.

https://www.contemporaryfashionpractices.com/curated-space-2020/leica-johnson 


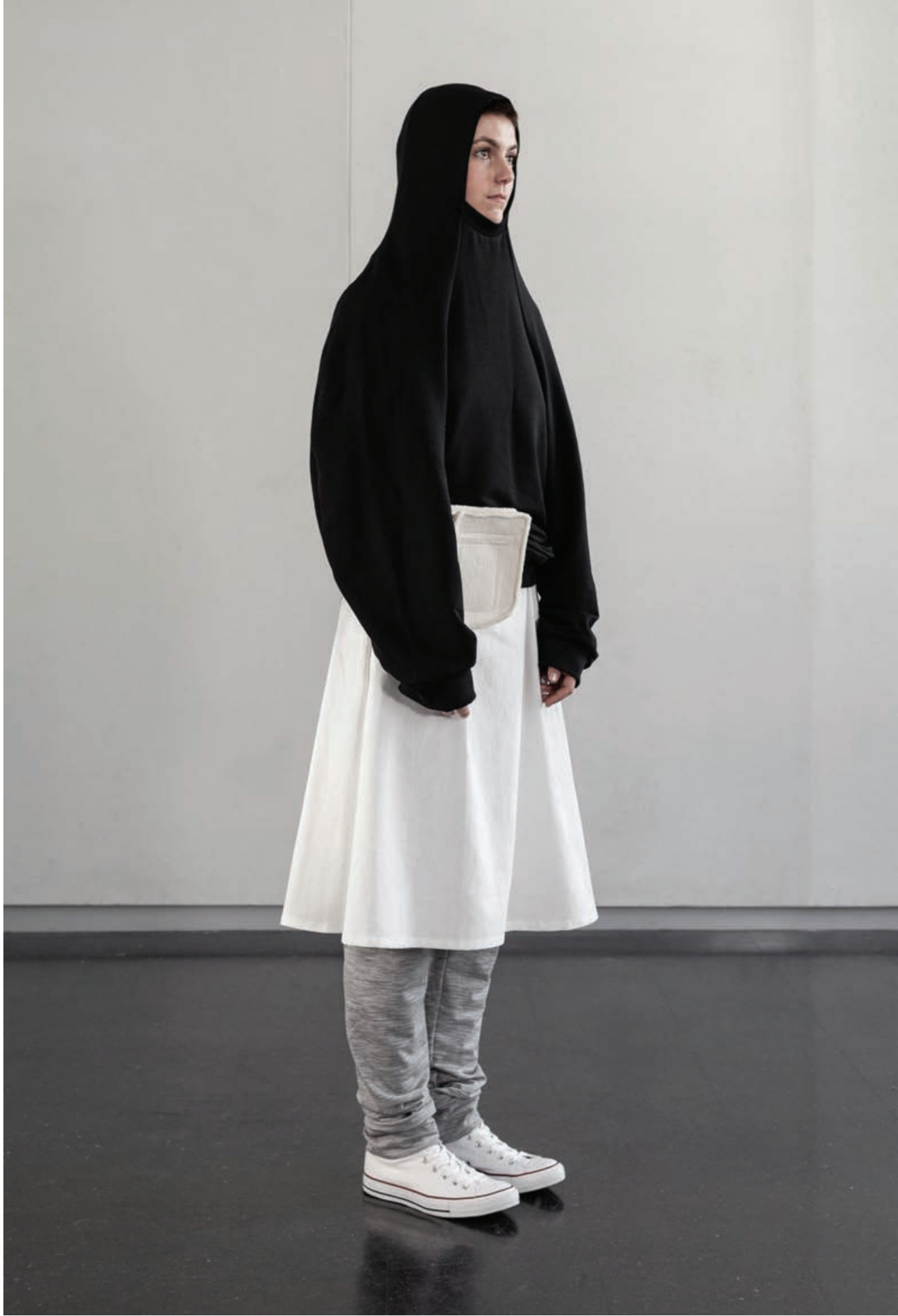

Figure 40. Hidden. Item 10. Hood,

worn over Item 15. Smock, and Item 12. Sweatpants.

Accessorised with Item I. Mini pocket bum bag. 


\section{Susan Marshall}

\section{Italy / UK \\ When is a crinoline not a crinoline?}

Costume as "travelling scenography" and concepts of play lie behind Susan's threedimensional yet flat-packable portable modular forms. These crinoline shapes can be zipped together, worn on arms, legs or heads, treated as abstract shapes or clothing. Collaboration with dancer/actress Tilde Knudsen furthered the design and variety of her forms.

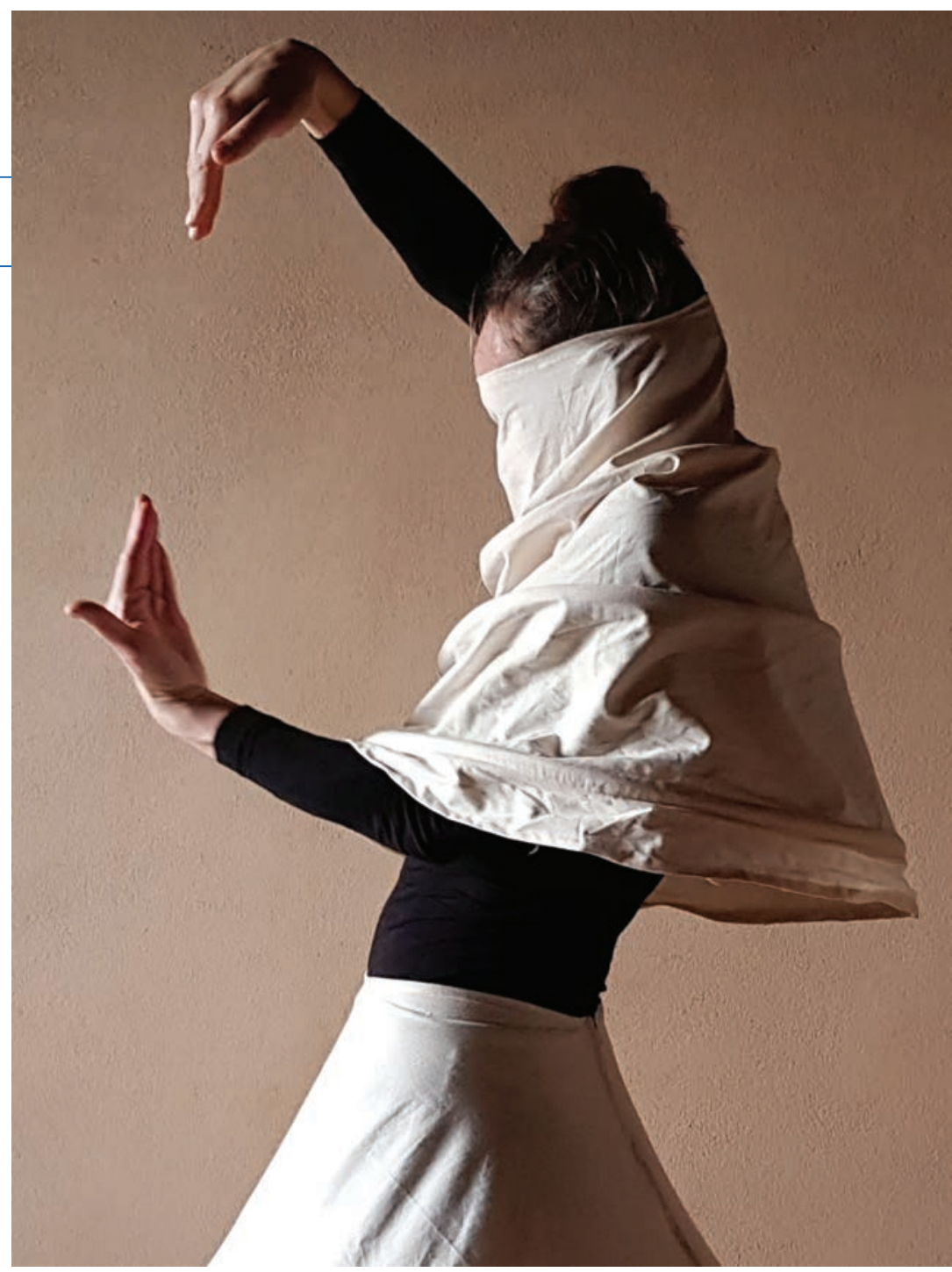

Figure 4I. Insubordinate Costume: Alice in Wonderland Walrus. 2020. Photograph: Emile Carlsen.

Susan Marshall is a costume designer, design historian, artist and lecturer based in Italy and the UK. She lectures on twentieth-century fashion in the Fashion Institute of Technology (FIT), a department within the Politecnico di Milano, and is undertaking a PhD at Goldsmiths, University of London, exploring the pivotal role of scenographic costume in performance and examining the role of play in the performers' creative approach.

\begin{tabular}{ll} 
website: & http://www.susanmarshall.info/ \\
\hline instagram: & $\begin{array}{l}\text { https://www.instagram.com/ } \\
\text { insubordinate_costume/ }\end{array}$ \\
\hline facebook: & $\begin{array}{l}\text { https://www.facebook.com/susan. } \\
\text { marshall.566/4 }\end{array}$
\end{tabular}

https://www.contemporaryfashionpractices.com/curated-space-2020/susan-marshall 


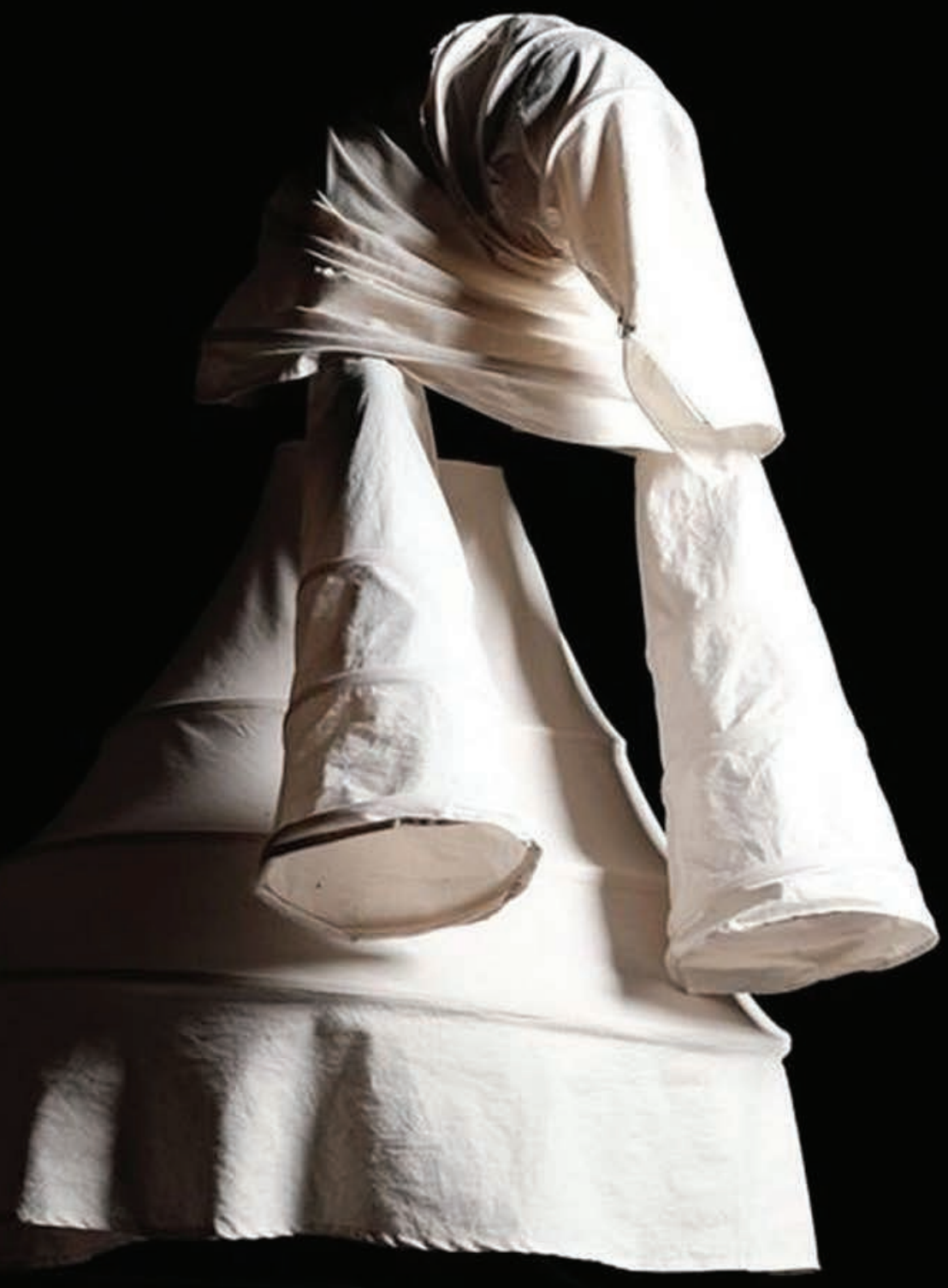

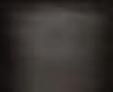

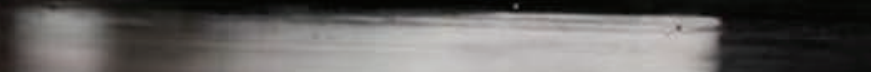




\section{Tamar Kikoria}

UK / Georgia

\section{The World Turned Upside Down:Thinking through Making}

Tamar designs for longevity, adaptability and versatility using digital and hand crafting. She has investigated creating historical design elements such as ruffs, cuffs and garment slashes using experimental and digital techniques in the context of slow and sustainable fashion. Components of her designs can be mixed to create multiple different looks, which allows the wearer as well as the designer to think through making.

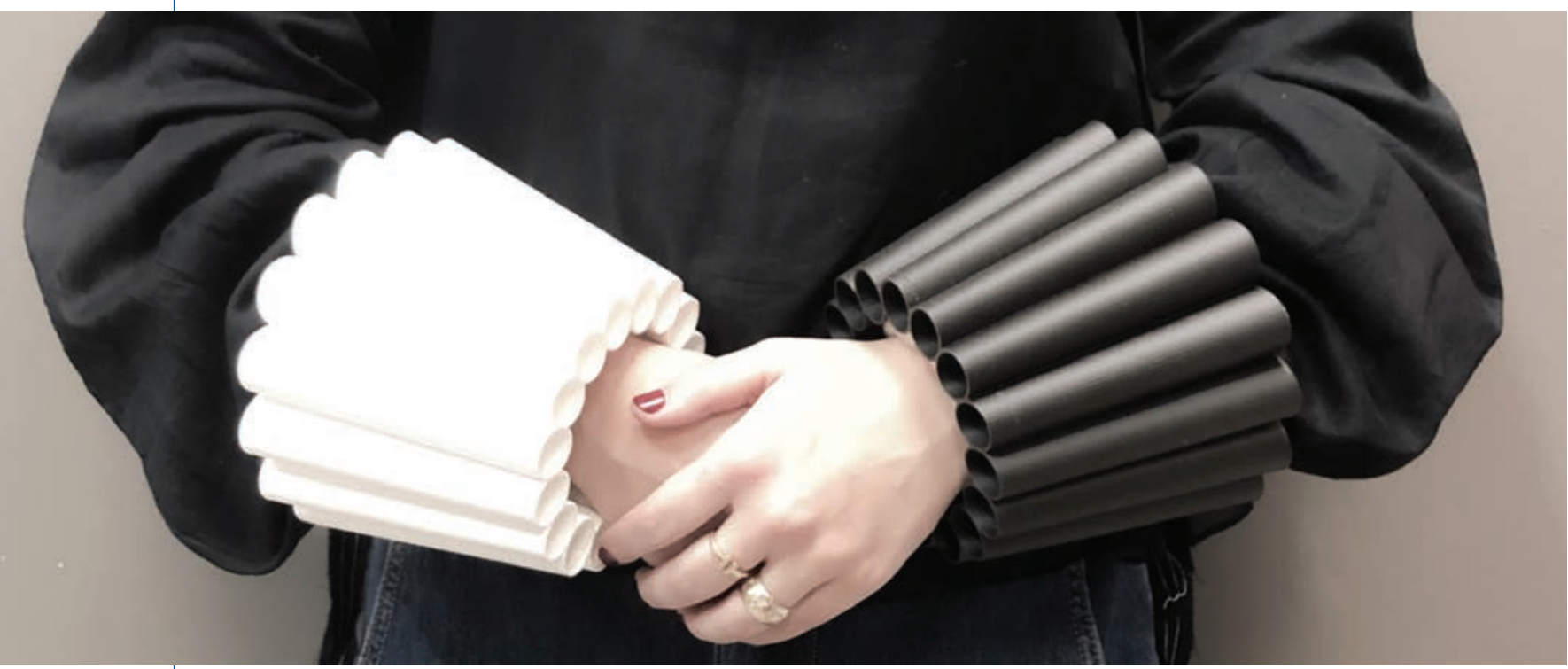

Figure 43. The World Turned Upside Down:Thinking through Making

Technological experimentation: 3D printing parts of the garment with bio-degradable materials.

Originally from Tbilisi, Georgia, Tamar Kikoria is a fashion designer based in London, UK. Tamar has a multidisciplinary approach to design, with a strong focus on research, development and craft design. Her work is inspired by historical dress and human craftsmanship around the world. She is keenly interested in technological innovations and their application to design. She has an MA in fashion design from Istituto Marangoni London and a BA in business administration from IE University Madrid, Spain. Tamar completed a one-year Intensive Fashion Design programme at Istituto Marangoni Milan (cum laude) and a Summer Intensive Fashion Design course at Parsons Paris.

\begin{tabular}{ll} 
email: & Takokikoria@gmail.com \\
\hline website: & TAMARKIKORIA.COM \\
\hline instagram: & @tamarakikoria \\
\hline
\end{tabular}

https://www.contemporaryfashionpractices.com/curated-space-2020/tamar-kikoria 

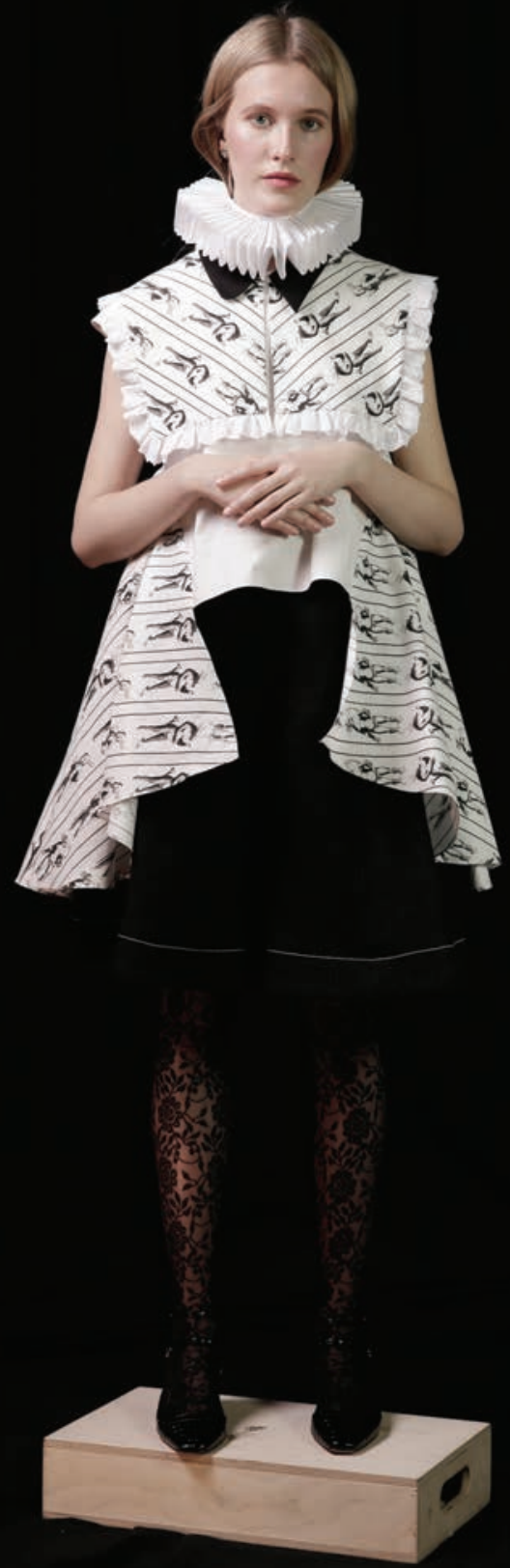


\section{Guoxiang Yuan}

China

\section{Ocean Waves}

Guoxiang Yuan used a contactless CO2 laser treatment integrated with computer-aided design (CAD) to pattern the surface of sewn garments. At optimised parameters the technique is repeatable and environmentally friendly, since it does not involve the use of water, dyestuff or solvents. It has possible commercial applications through enabling a rapid response to market demands.

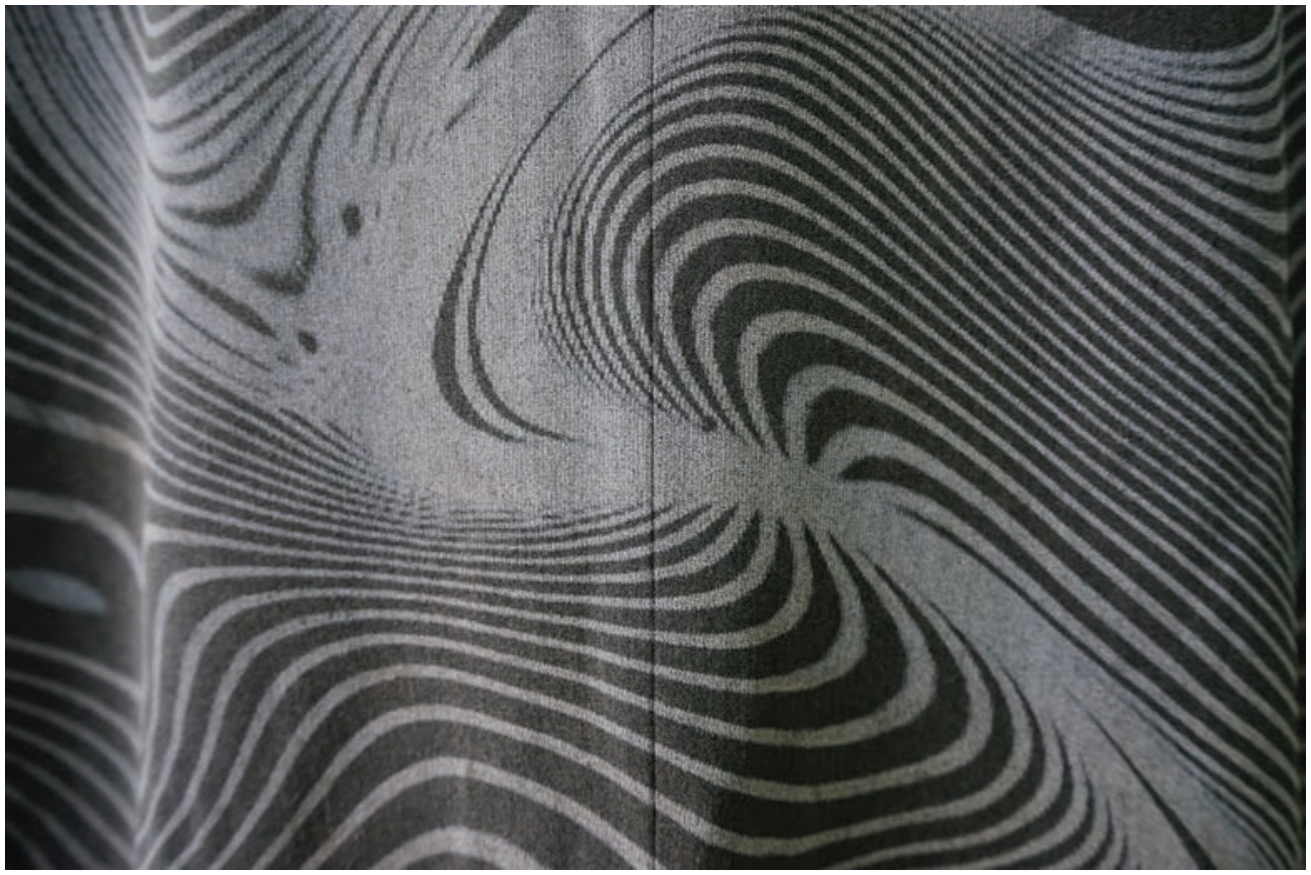

Figure 45, 46, 47. Ocean Waves. Design I, details.

Dr Guoxiang Yuan is an associate professor at the College of Fashion and Design, Donghua University, Shanghai, China. He is also a textile design advisor at China Menswear Design Trading Center, a member of the World Crafts Council - Asia Pacific Region, and a member of the Surface Design Association. Guoxiang Yuan's work has been exhibited internationally, and he has received a variety of design awards ranging from the Junichi Arai Award at the 8th International Shibori Symposium to the Excellence Award in the China Fur Capital Fur Design Competition. His work is represented in the collections of the China National Silk Museum. 

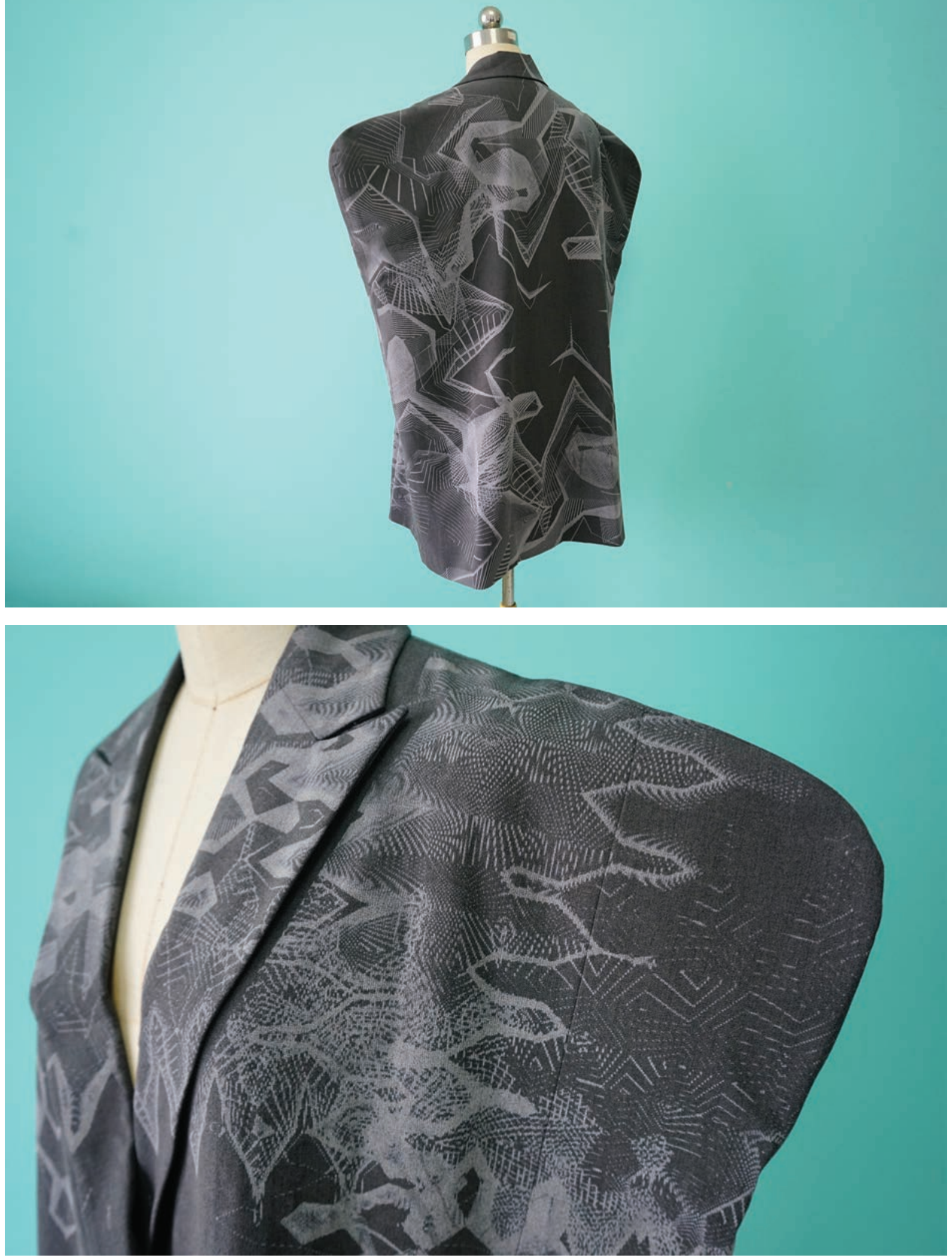